\title{
Computational Simulations of a Mach 0.745 Transonic Truss-Braced Wing Design AIAA-2020-1649
}

Daniel Maldonado, Jeffrey A. Housman, Jared C. Duensing, James C. Jensen, Cetin C. Kiris NASA Ames Research Center

Sally A. Viken, Craig A. Hunter, Neal T. Frink, S. Naomi McMillin, NASA Langley Research Center

AIAA SciTech, January $6^{\text {th }}-10^{\text {th }}, 2020$

Orlando, Florida 


\section{Outline}

- Introduction / Objectives

- Computational Methods

- Codes

- Modeling Procedure

- Verification Process

- Grid Refinement Study

- Verification on Flight Geometry

- Validation with Wind Tunnel Data

- Free Air

- Wind Tunnel

- Geometry Sensitivity Study

- Summary 


\section{Introduction}

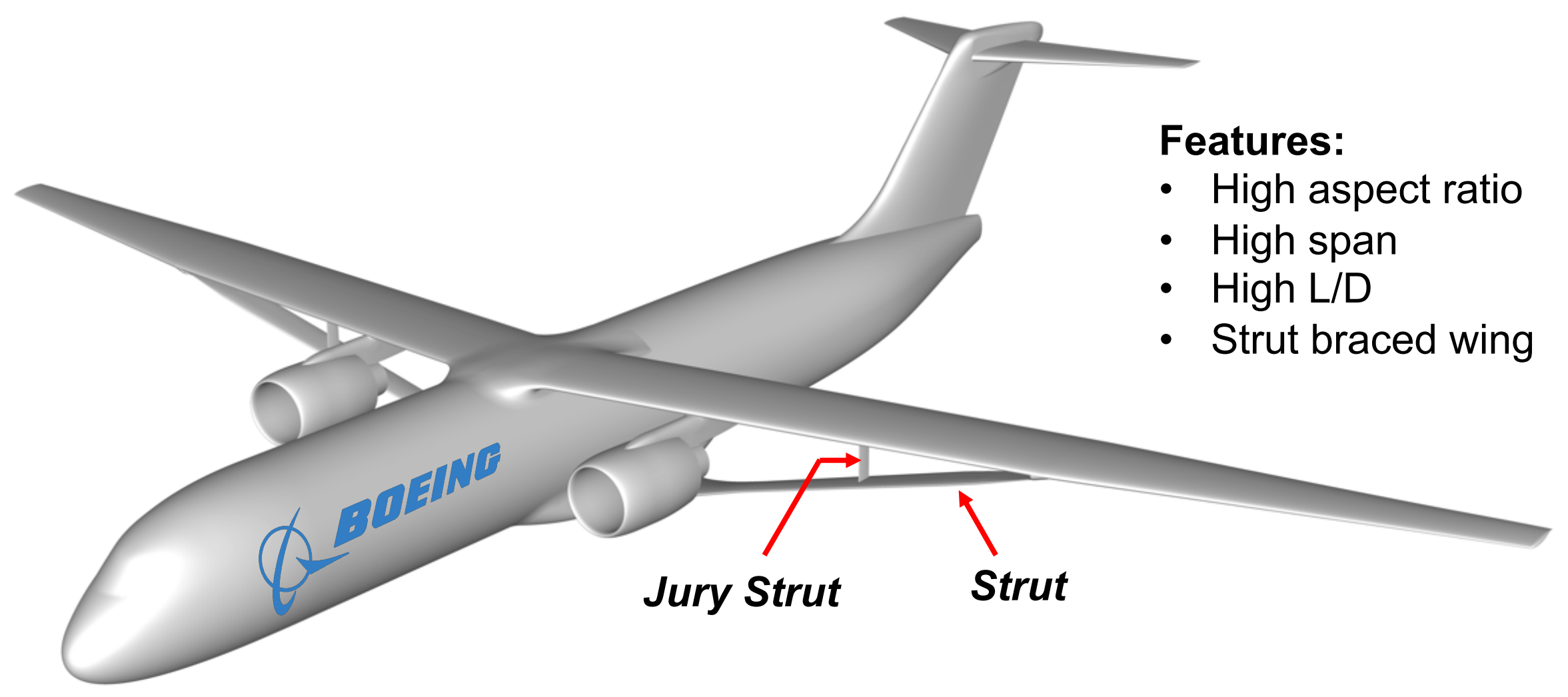

\section{Boeing Transonic Truss-Braced Wing (TTBW)}

Mach 0.745 Variant 


\section{Objectives}

- Establish best practices for NASA CFD codes for Transonic Truss-Braced Wing-like configurations.

- Utilize two grid paradigms

- unstructured mixed-element

- curvilinear structured overset

- Perform validation study of CFD results compared to TTBW wind tunnel experiments. 


\section{Description of NASA CFD Codes}

Launch Ascent and Vehicle Aerodynamics (LAVA)

- Vertex-based RANS

- $\quad 2^{\text {nd }}$ order finite difference formulation

- Structured curvilinear overlapping grids

- Spalart-Allmaras turbulence model

- Rotation / Curvature Correction (RC)

- Quadratic Constitutive Relationship (QCR2000)
USM3D from TetrUSS (Tetrahedral Unstructured Software System)

- Cell-centered RANS

- $\quad 2^{\text {nd }}$ order finite volume formulation

- Mixed-element unstructured meshes

- Spalart-Allmaras turbulence model

- With and without QCR2000 


\section{Structured Overset Grid Generation}

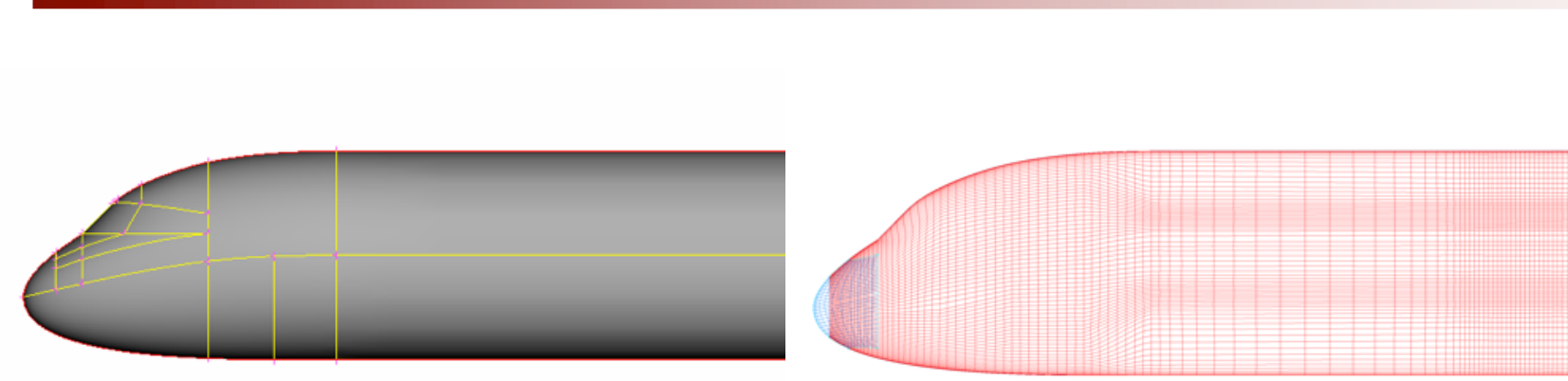

1. Geometry clean up and preparation using ANSA

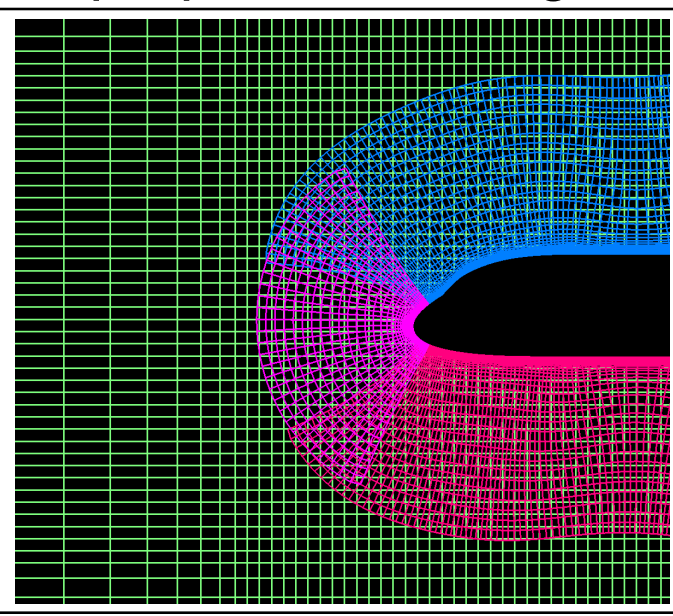

4. Domain Connectivity using DCF Module of OVERFLOW
2. Surface mesh generation using Pointwise

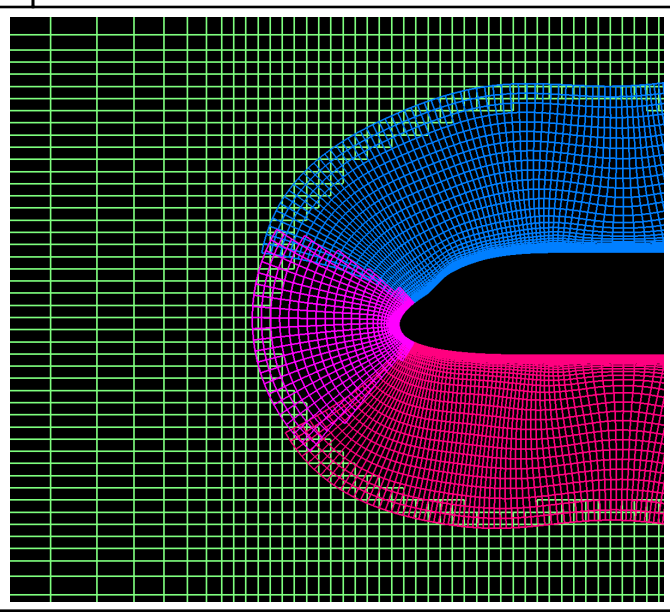

5. Minimized overlap regions between grid using LAVA MIHC
3. Volume mesh generation using Chimera Grid Tools (CGT)

- Maintaining a $y^{+} \leq 1$

- Double fringe

- Consistent first layer spacing across all viscous walls

- Half model with symmetry plane

Other Guidelines 


\section{Unstructured Mixed-Element Grid Generation}

1. IGES CAD imported into Heldenmesh

2. Generate triangulated surface mesh

3. Adjust first layer height to $y^{+} \approx 1$. First cell centroid of approximately $y^{+}=0.5$.

4. Cell to cell growth rate of $11-14 \%$

5. Mixed-element mesh with 32 layers of prismatic cells for the boundary layer

6. Pyramidal cell transition to tetrahedral meshes in the outer grid

7. Half Model with Symmetry Plane
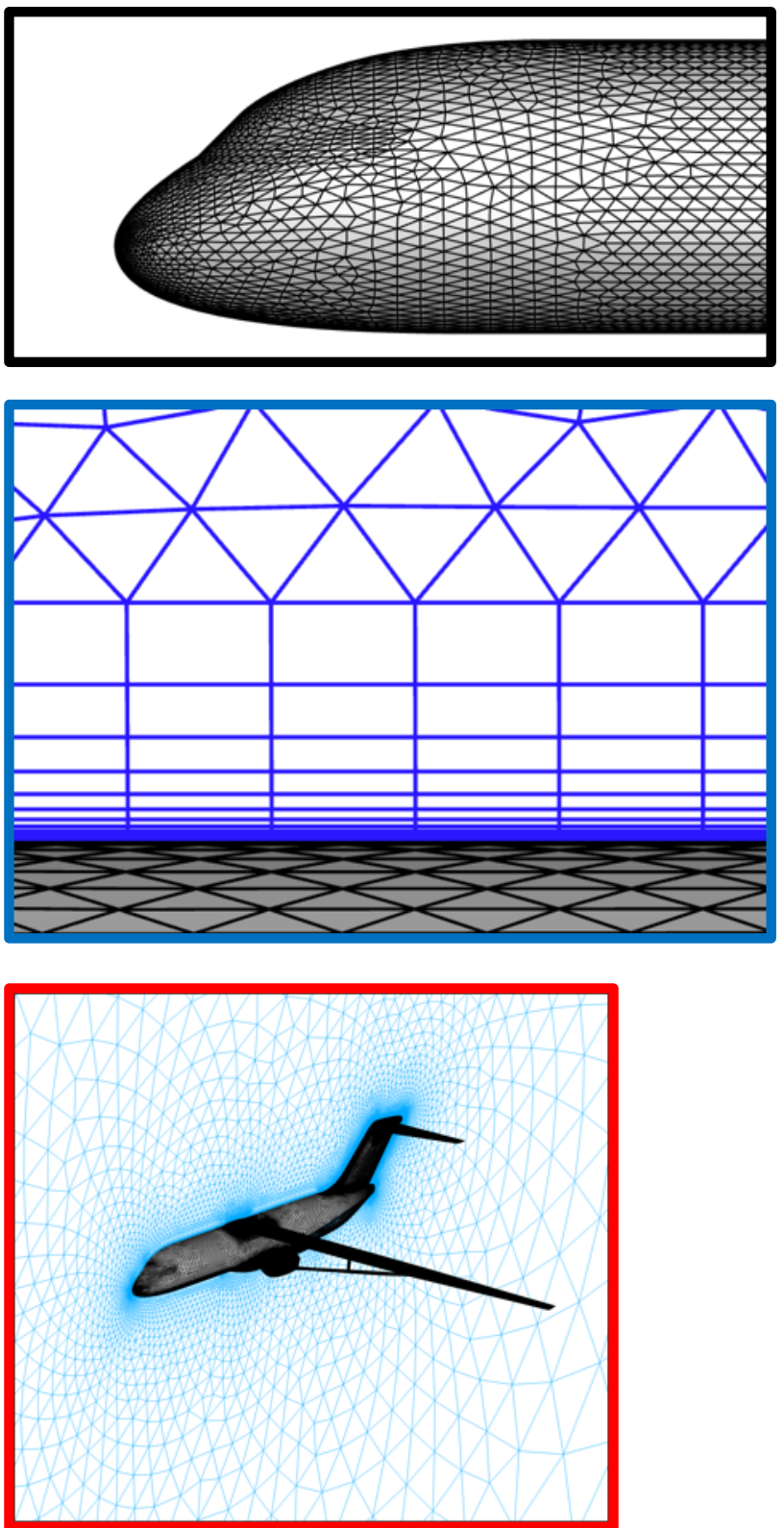


\section{Verification and Code to Code Comparison}

- Code to code comparison was done to remove sensitivity to grid type from the simulation, quantify the uncertainty, and help diagnose cause of discrepancies with experimental results

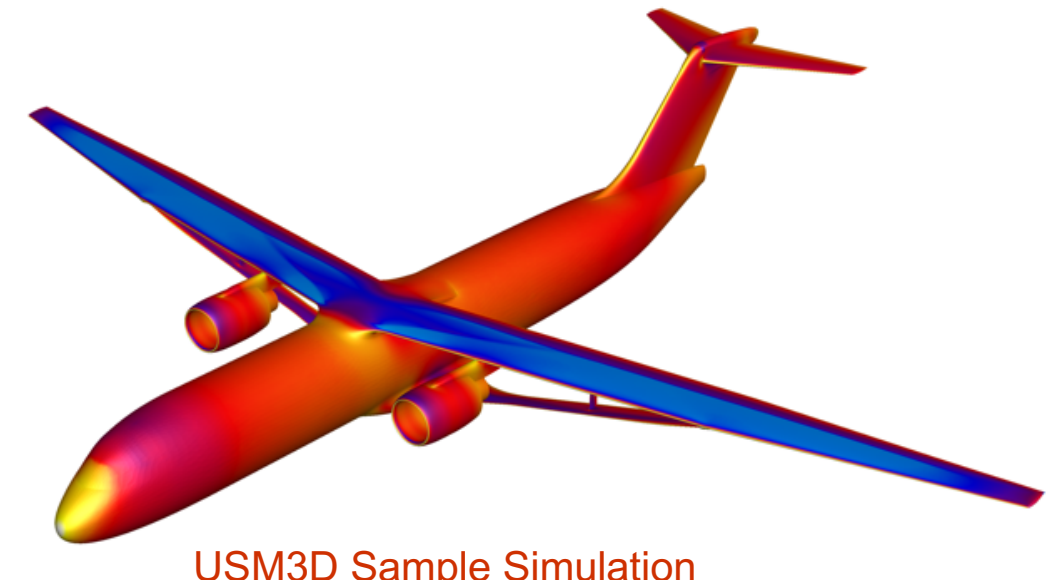

USM3D Sample Simulation

LAVA

- Grid convergence study

- Angle of attack effect on grid convergence

- Flux discretization effect on grid convergence

- Wake grid

- Angle of Attack sweep with best practices
USM3D

- Grid convergence study

- Angle of attack effect on grid convergence

- SA vs SA-QCR2000

- Angle of Attack sweep with best practices 


\section{Structured Overset Grid Refinement Process}

- A scale factor $(S F)$ is used for each refinement level

- 3 Refinement Levels created.

- Coarse $(S F=1)$, Medium $(S F=1.4)$, Fine $(S F=2.0)$

- Surface grids are refined in Pointwise using script

- Edge spacing scaled by inverse of SF

- Number of points scaled by SF

- Scripts used to generate volume grids with CGT have SF built-in to account for any refinement level

Resulting Volume Grids

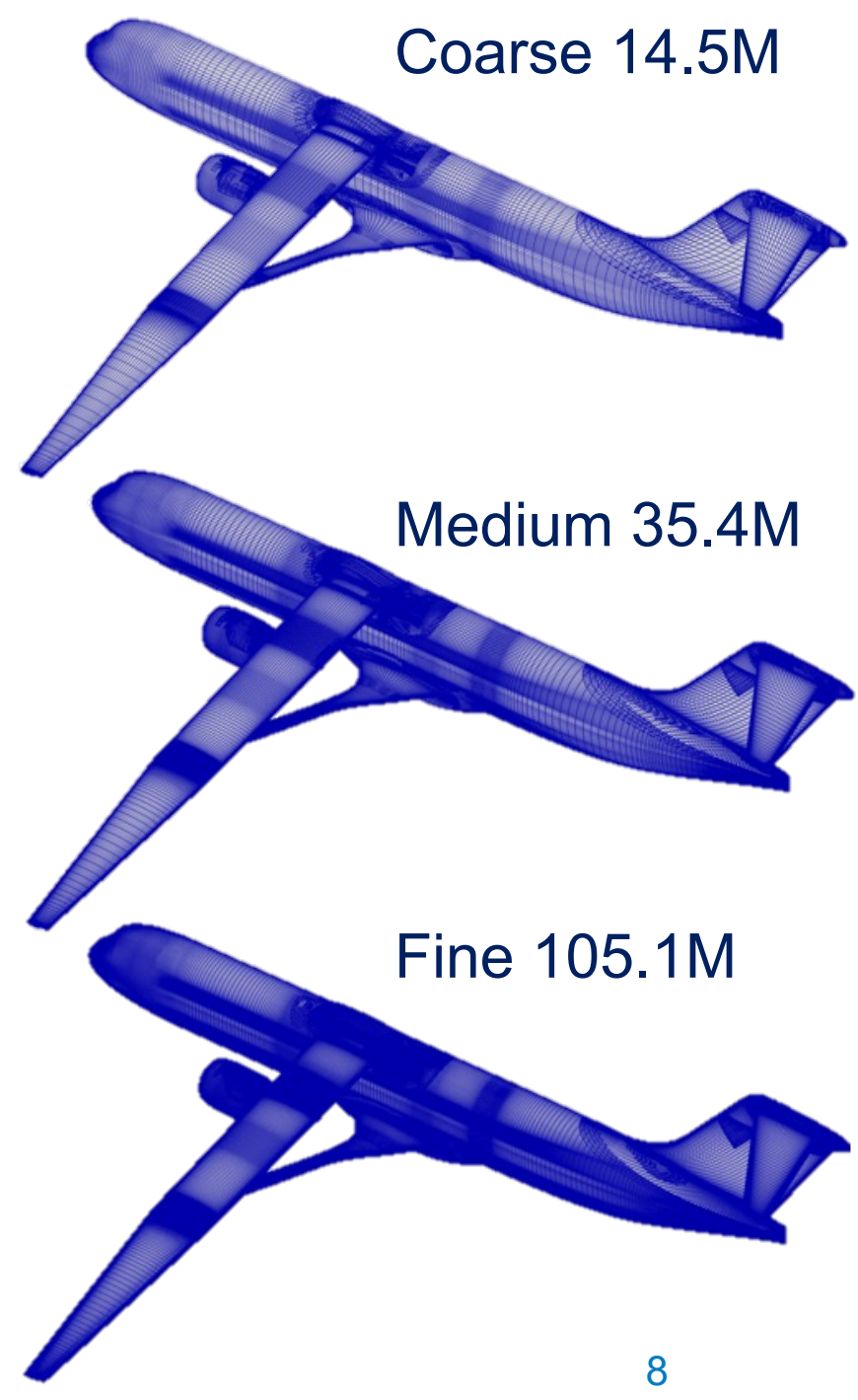




\section{Unstructured Mixed-Element Grid Refinement Process}

- Three refinement levels are created.

- Coarse, Medium, Fine

- Mesh refinement and coarsening using Heldenmesh

- Grid sourcing scaled by approximately $1 / \sqrt{2}$ and $\sqrt{2}$ to obtain finer and coarser meshes

- Scaling of $1 / \sqrt{2}$ and $\sqrt{2}$ applied to surface mesh, viscous layers, and volume mesh.

Coarse $18.5 \mathrm{M}$

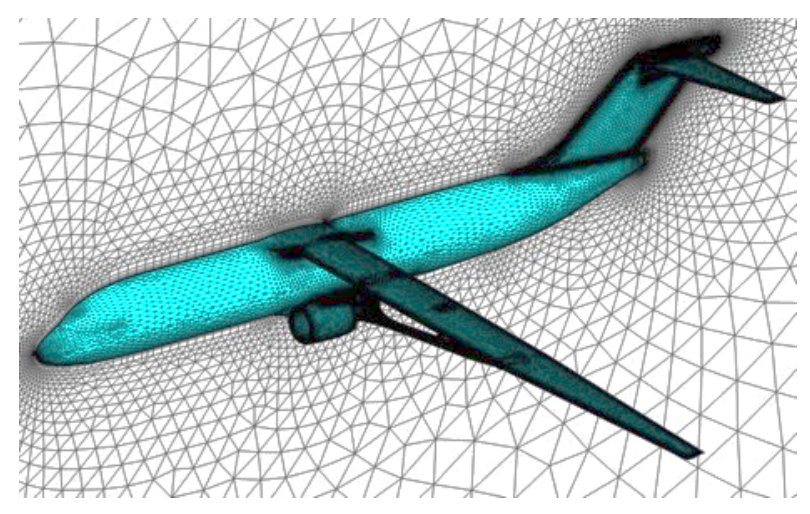

Medium 31.3M

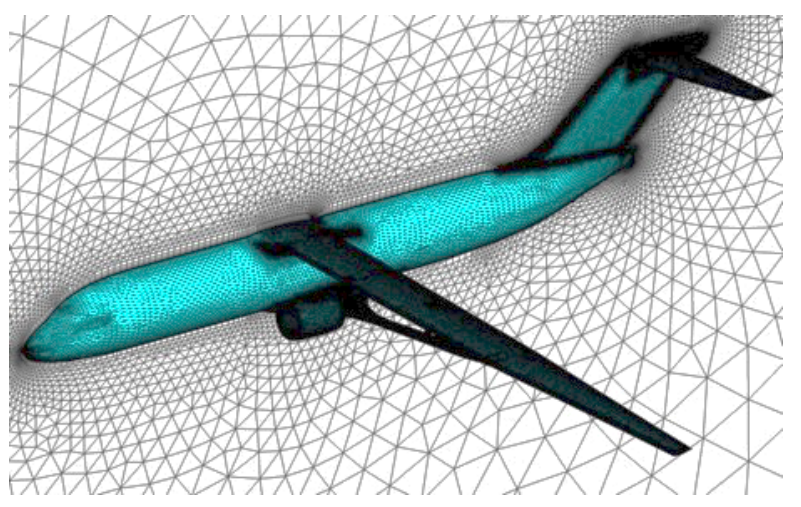

Fine 59.4M

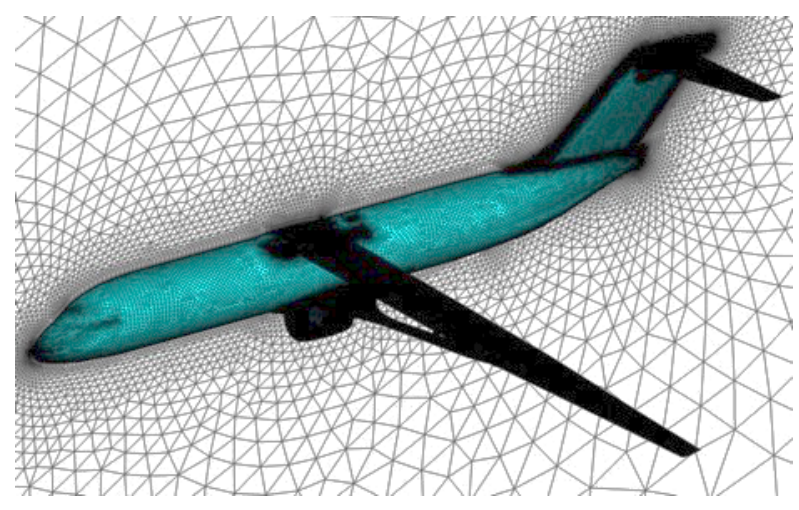




\section{Grid Convergence Comparison - LAVA and USM3D}

- For evaluating convergence, the loads of the 3 different grid levels are plotted against $N^{-2 / 3}$.

- Linear fit used to evaluate asymptotic convergence and estimate the load value for infinitely refined grid
- LAVA SA-RC-QCR compared with USM3D SA-QCR

- Conditions:

- Altitude at 40,000 feet

- Temperature $=389.97{ }^{\circ} R$

- Mach 0.745

$-R e_{c}=13.1 \times 10^{6}$
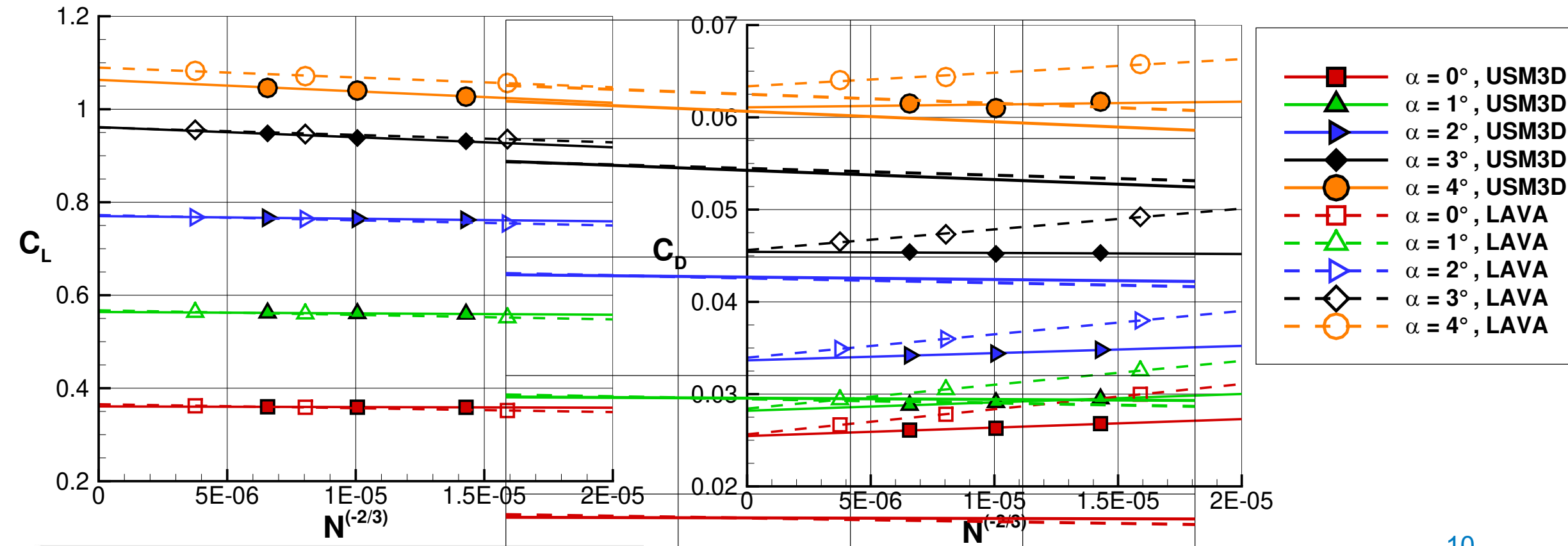


\section{Grid Convergence Comparison - LAVA and USM3D}

\section{Comparison of loads at $\alpha=2^{\circ}$}

LAVA SA-RC-QCR2000

\begin{tabular}{|l|c|l|l|l|}
\hline $\begin{array}{l}\text { Refinement } \\
\text { Level }\end{array}$ & $\begin{array}{l}\text { Nodes } \\
\text { (Million) }\end{array}$ & $\mathbf{C}_{\mathbf{L}}$ & $\mathbf{C}_{\mathbf{D}}$ & $\mathbf{C}_{\boldsymbol{m}}$ \\
\hline Coarse & 14.5 & 0.7543 & 0.03798 & -0.1097 \\
\hline Medium & 36.4 & 0.7640 & 0.03599 & -0.1184 \\
\hline Fine & 105.1 & 0.7677 & 0.03490 & -0.1246 \\
\hline Asymptote & $\infty$ & 0.7732 & 0.03375 & -0.1297 \\
\hline
\end{tabular}

USM3D SA-QCR2000

\begin{tabular}{|l|c|l|l|l|}
\hline $\begin{array}{l}\text { Refinement } \\
\text { Level }\end{array}$ & $\begin{array}{l}\text { Cells } \\
\text { (Million) }\end{array}$ & $\mathbf{C}_{\mathrm{L}}$ & $\mathbf{C}_{\mathrm{D}}$ & $\mathrm{C}_{\mathrm{m}}$ \\
\hline Coarse & 18.5 & 0.7621 & 0.03480 & -0.1278 \\
\hline Medium & 31.3 & 0.7643 & 0.03439 & -0.1285 \\
\hline Fine & 59.4 & 0.7665 & 0.03421 & -0.1298 \\
\hline Asymptote & $\infty$ & 0.7702 & 0.03367 & -0.1313 \\
\hline
\end{tabular}

Difference between codes

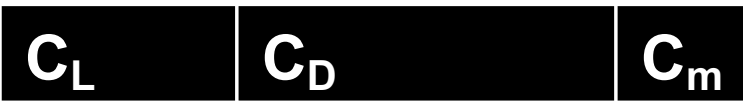

$0.39 \% \quad 0.8$ Counts $1.23 \%$




\section{Code to Code Comparison - AOA Sweep}
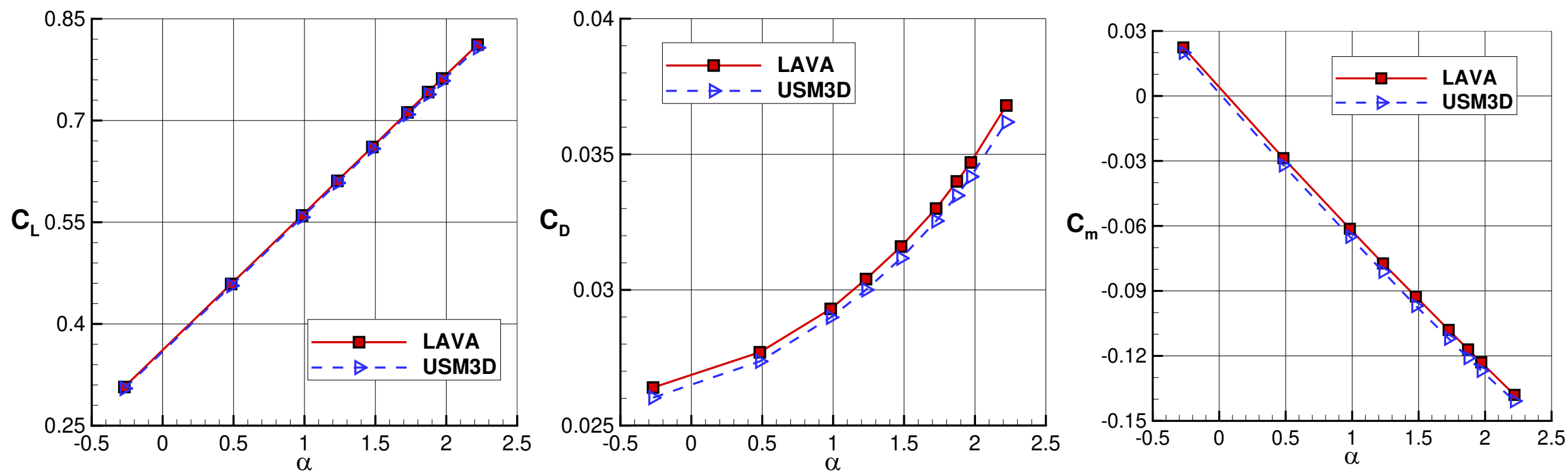

- LAVA SA-RC-QCR compared with USM3D SA-QCR

- The code to code comparison at flight conditions was successful in verifying the codes would arrive at a similar solution

- Throughout the sweep $C_{L}$ varied by $0.38-0.73 \%, C_{D}$ by 2.4 to 6.1 counts

- Slight shift in $\mathrm{C}_{\mathrm{m}}$ due to drag differences 


\section{Wind Tunnel Test - Background}

- A 4.5\% scale model was built to be tested in the NASA Ames Unitary Plan 11-foot Transonic Wind Tunnel (TWT).

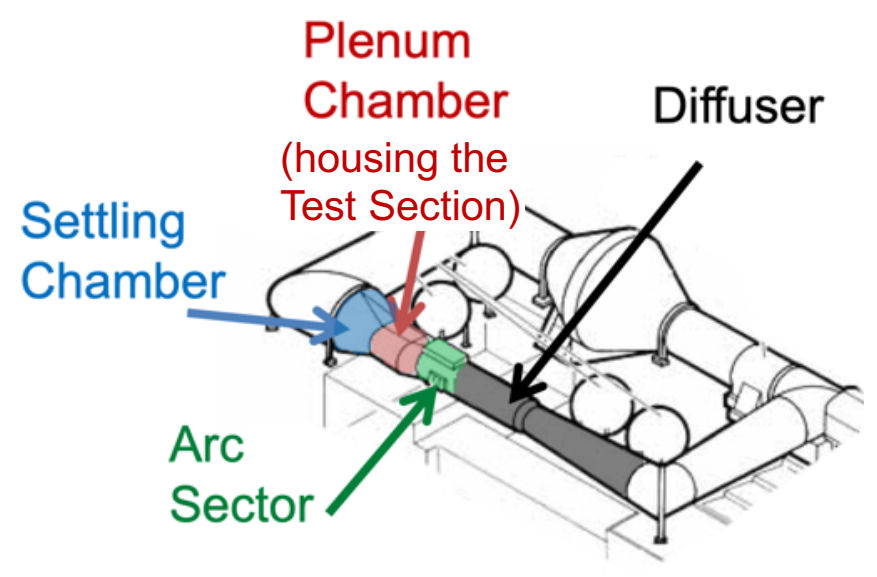

Schematic of 11ft TWT Courtesy of NASA

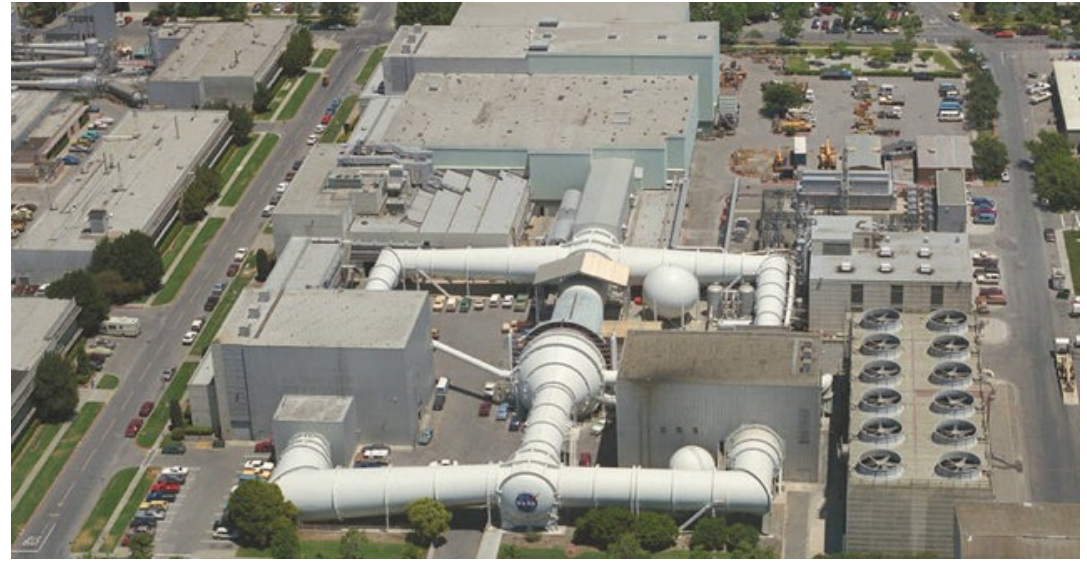

NASA Ames Unitary Plan Wind Tunnels Courtesy of NASA

- The 11-ft TWT is a closed-circuit fixed-geometry tunnel composed of a settling chamber, a ventilated test section enclosed by a plenum, an arc sector to actuate the model, and a diffuser. 


\section{Experimental Conditions and Data}

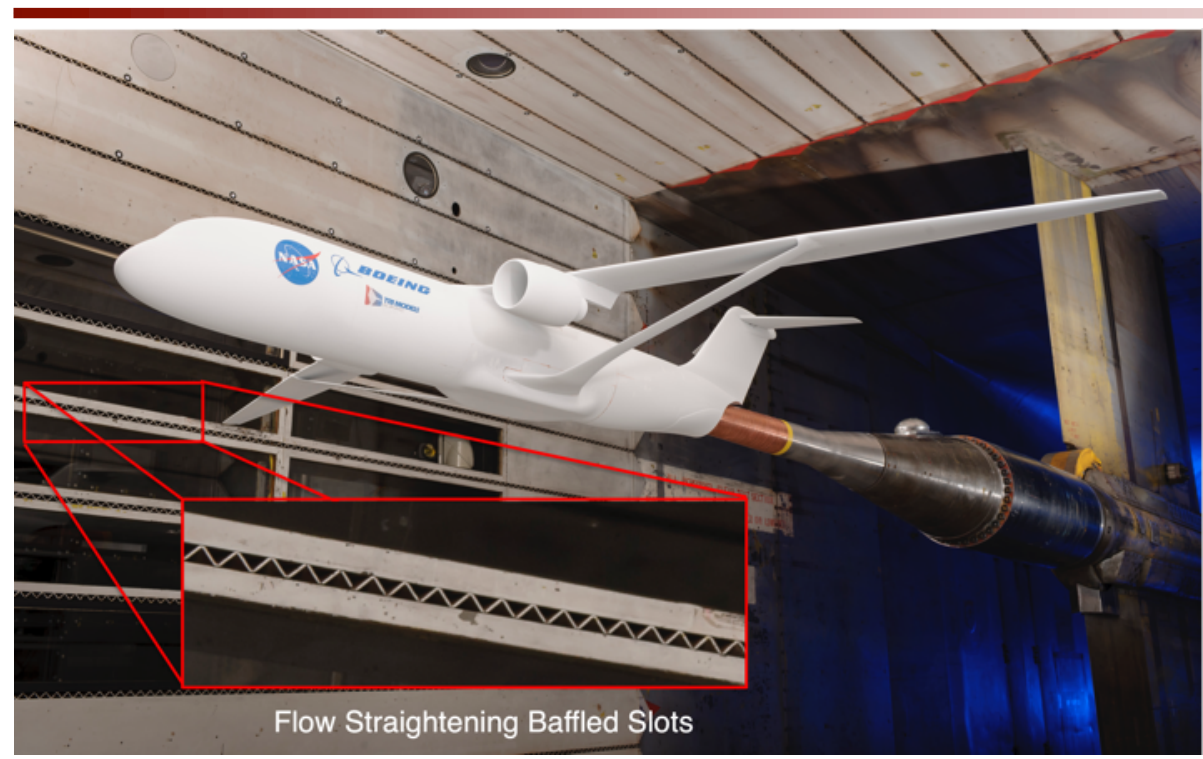

Mach 0.745 TTBW installed in 11ft TWT Courtesy of NASA

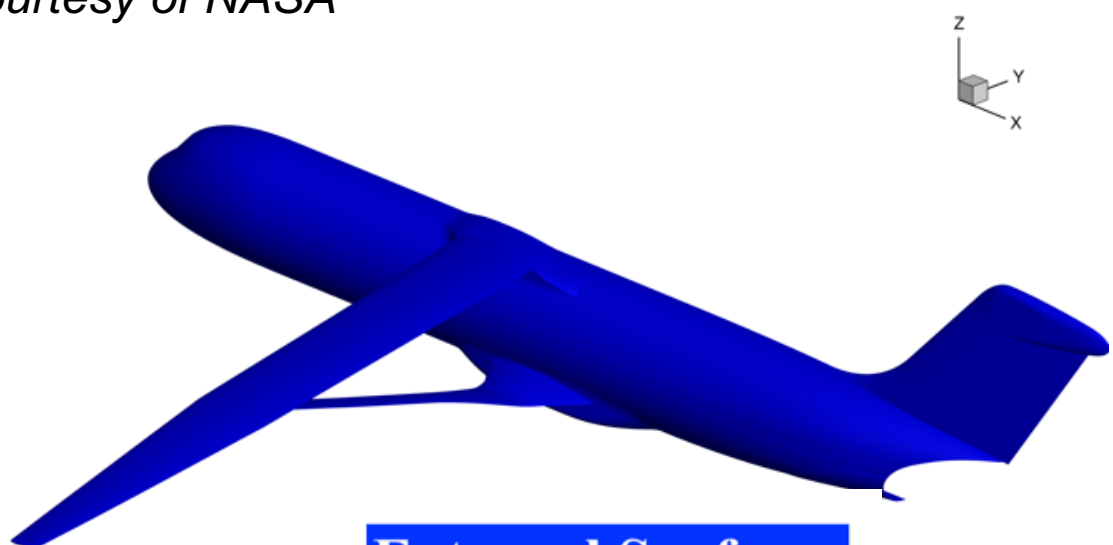

External Surfaces
- Wind Tunnel Data:

- Raw data (Uncorrected)

- Cavity Correction

- Accounts normal and axial forces and pitching moment inside of cavity where sting attaches to fuselage

- All corrections (Corrected)

- Approximates free air condition

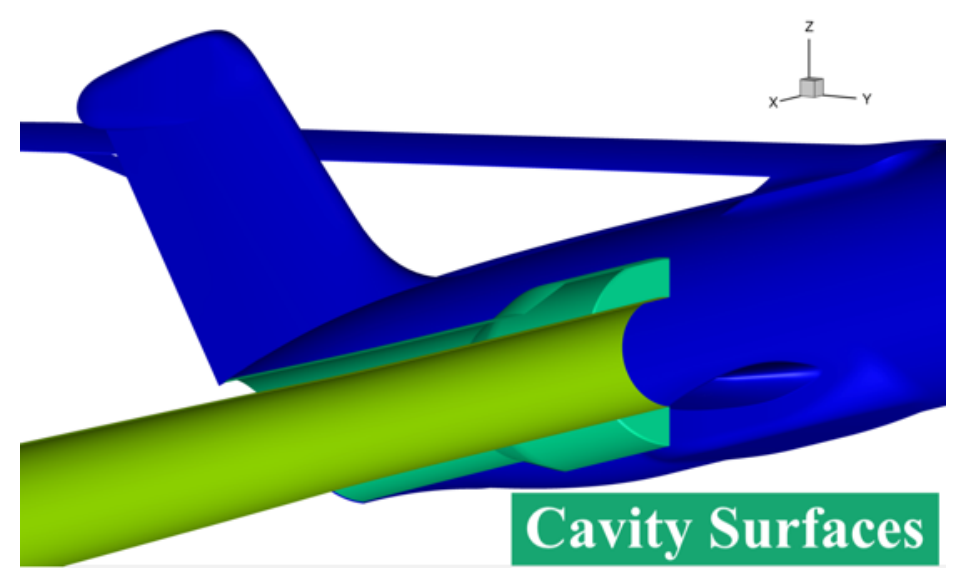




\section{Computational Geometry}

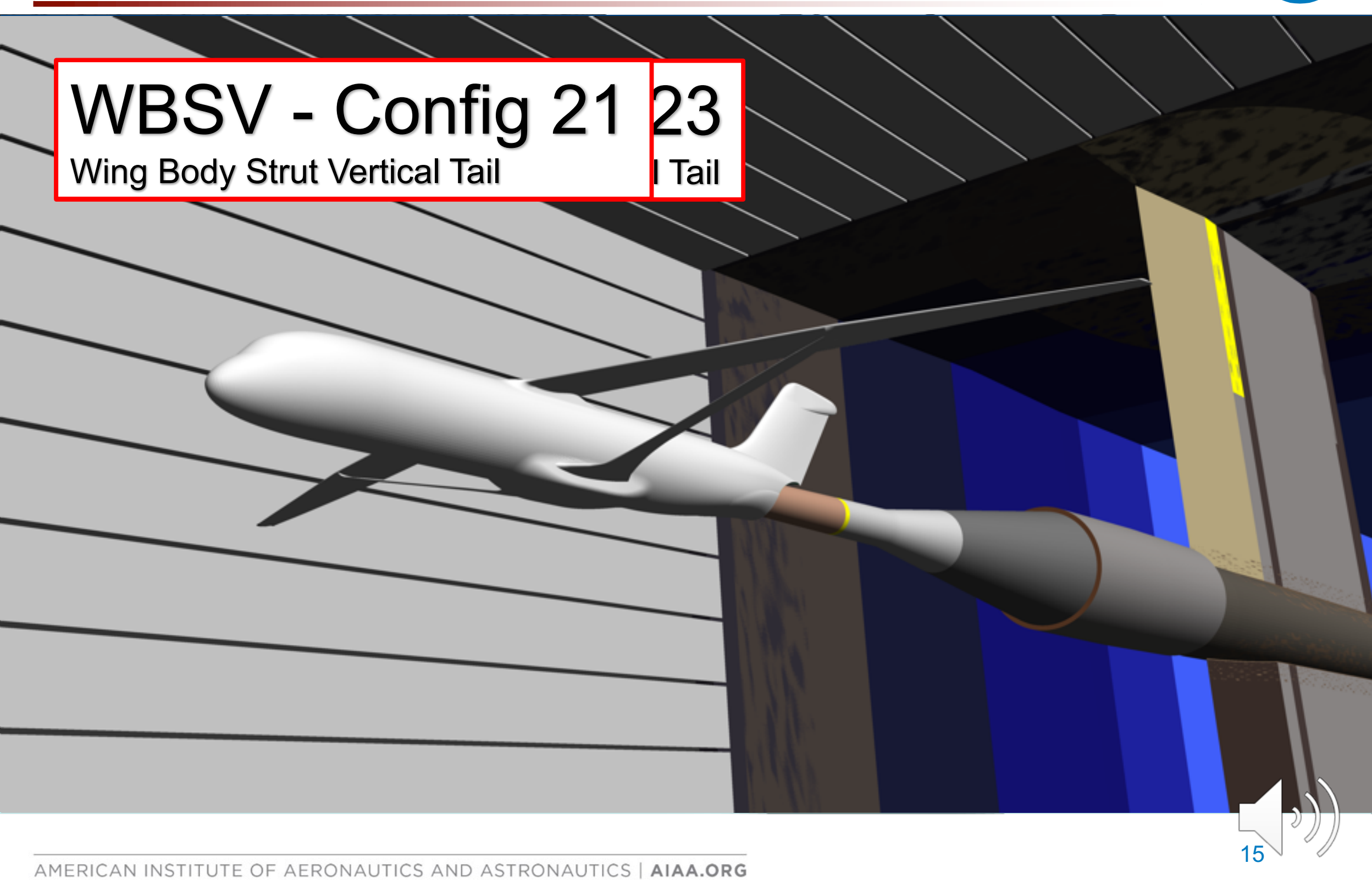




\section{Validation with Experimental Data}

\section{LAVA}

- Grid convergence studies

- Free-air simulations

- WBSV

- WBSNPV

- Slotted-wall wind tunnel simulations

- $2^{\text {nd }}$ Order Steady Rans

- Mixed Order Steady Rans

- $1^{\text {st }}$ Order Unsteady Rans

- Simplified wind tunnel

- Inviscid Channel

- Viscous Wall Wind Tunnel

- Porous Wall

- Full Body

- Half Body

- Sensitivity to Geometry Corrections

- Twisted Wing

- Trailing Edge

\section{USM3D}

- Grid convergence studies

- Free-air simulations

- WBSV

- WBSNPV

- SA vs SA-QCR2000
- Wind Tunnel Conditions:

- $\mathrm{T}_{\text {Freestream }} \approx 493^{\circ} \mathrm{R}$

- $\mathrm{T}_{\text {Stagnation }} \approx 550{ }^{\circ} \mathrm{R}$

- Mach 0.745

- $R e_{c}=3.31 \times 10^{6}$

$-2^{\circ}<\alpha \lesssim 4^{\circ}$ 


\section{Mesh for Wind Tunnel Validation}

- Grid refinement was run for both codes

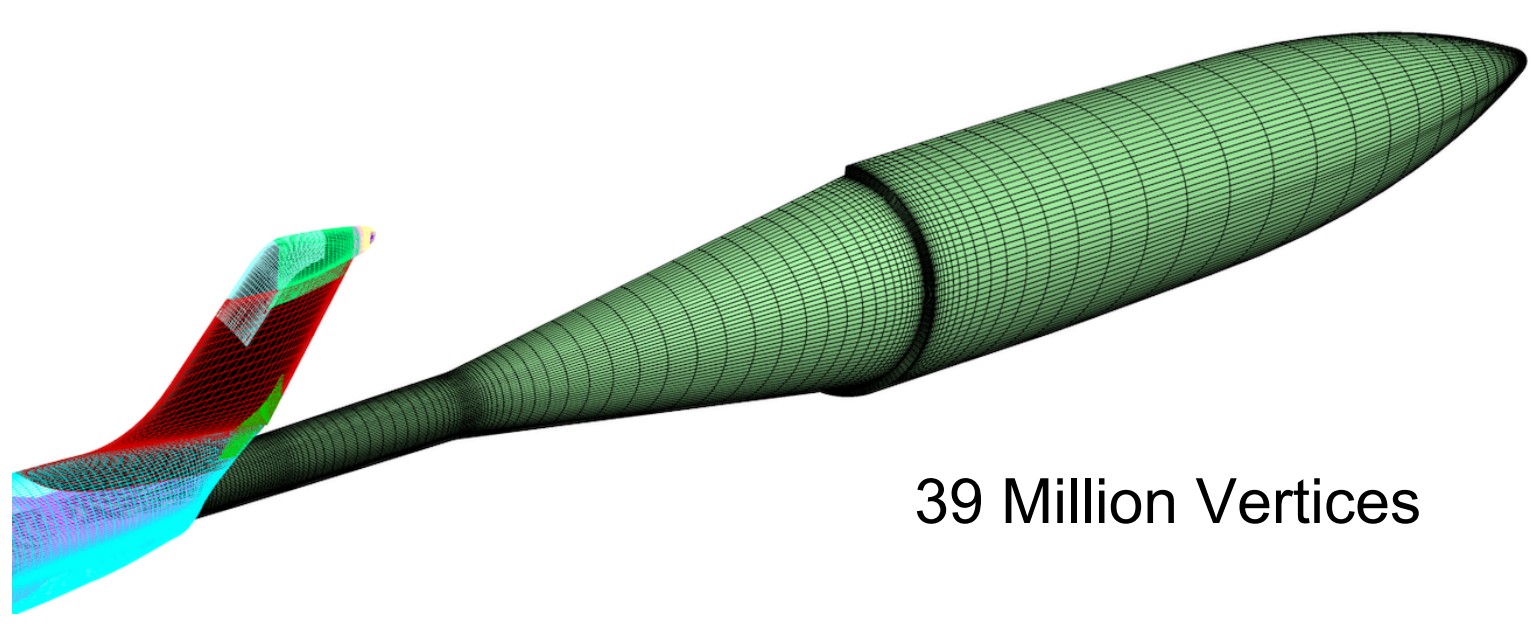

- LAVA simulations were run with a medium grid resolution rather than the fine grid to reduce computational cost

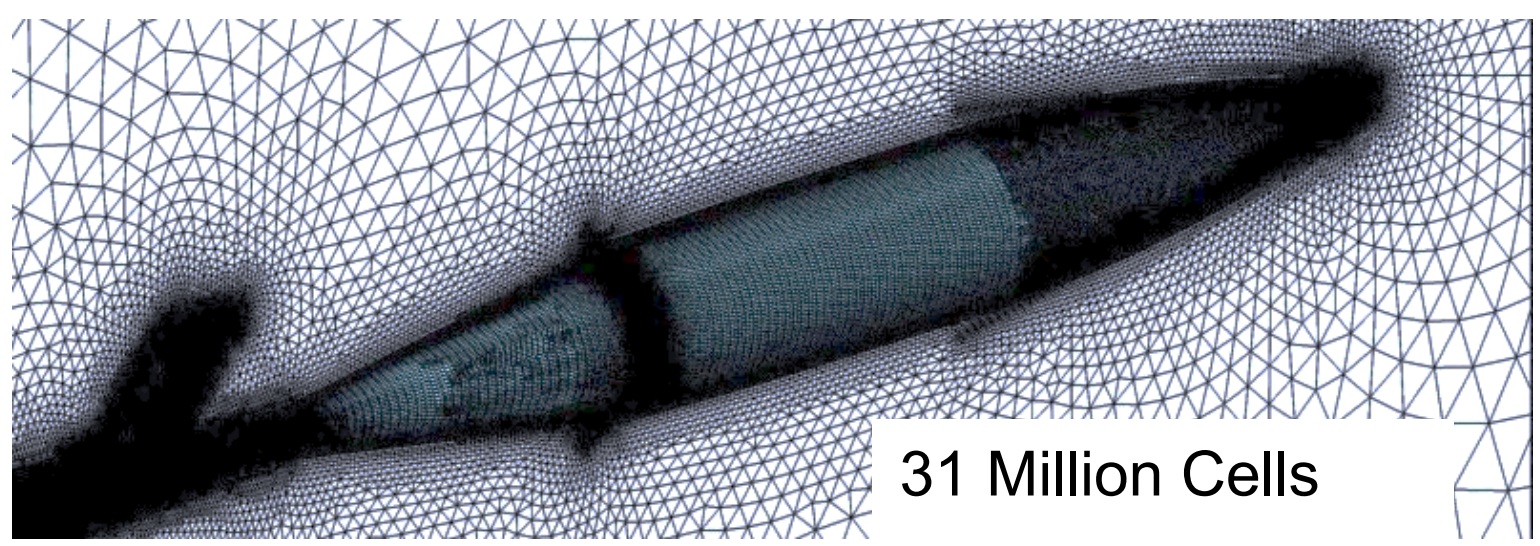

- USM3D found their medium grid to be sufficiently fine 


\section{Validation with Wind Tunnel Data}

\section{Free Air - WBSNPV Config 23}

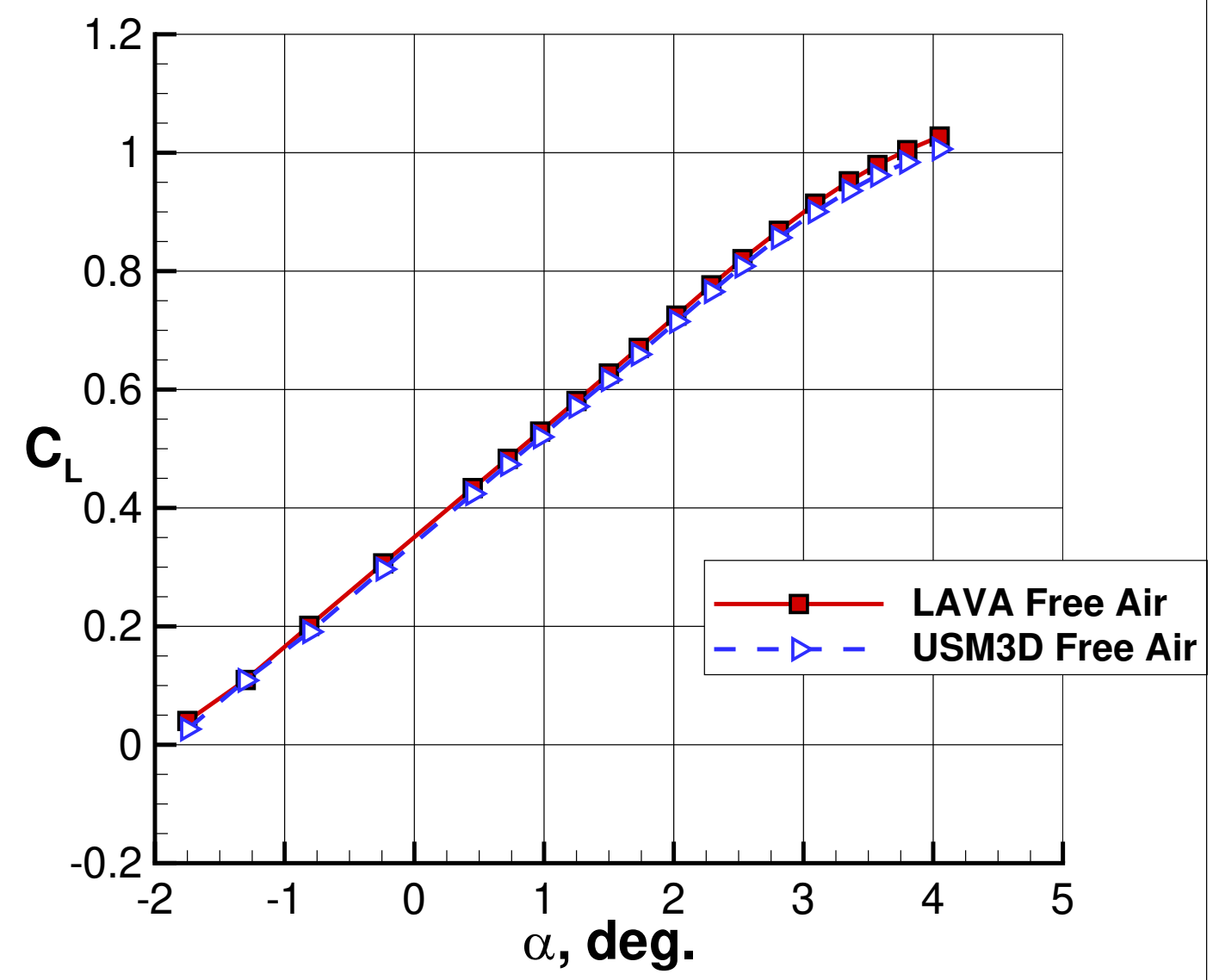

- Conditions:

$-\mathrm{T}_{\text {Freestream }} \approx 493^{\circ} \mathrm{R}$

- $\mathrm{T}_{\text {Stagnation }} \approx 550{ }^{\circ} \mathrm{R}$

- Mach 0.745

- $R e_{c}=3.31 \times 10^{6}$

$-2^{\circ}<\alpha \lesssim 4^{\circ}$

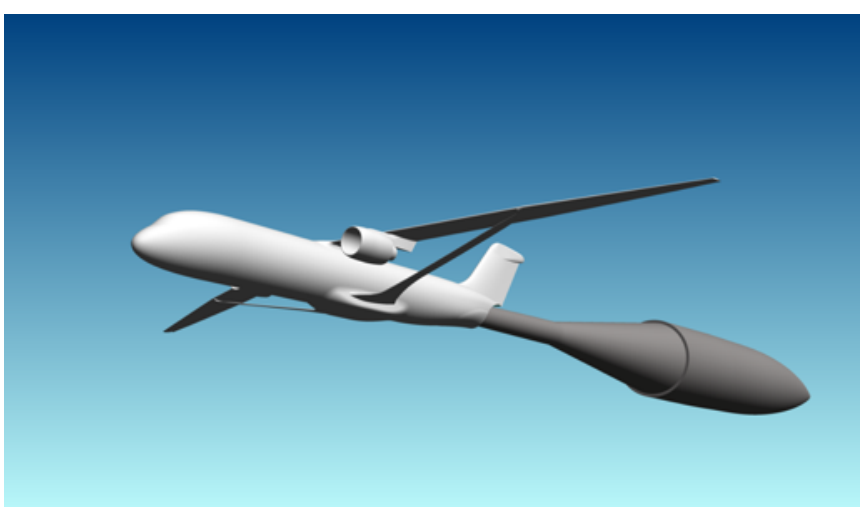




\section{Validation with Wind Tunnel Data}

\section{Free Air - WBSNPV Config 23}

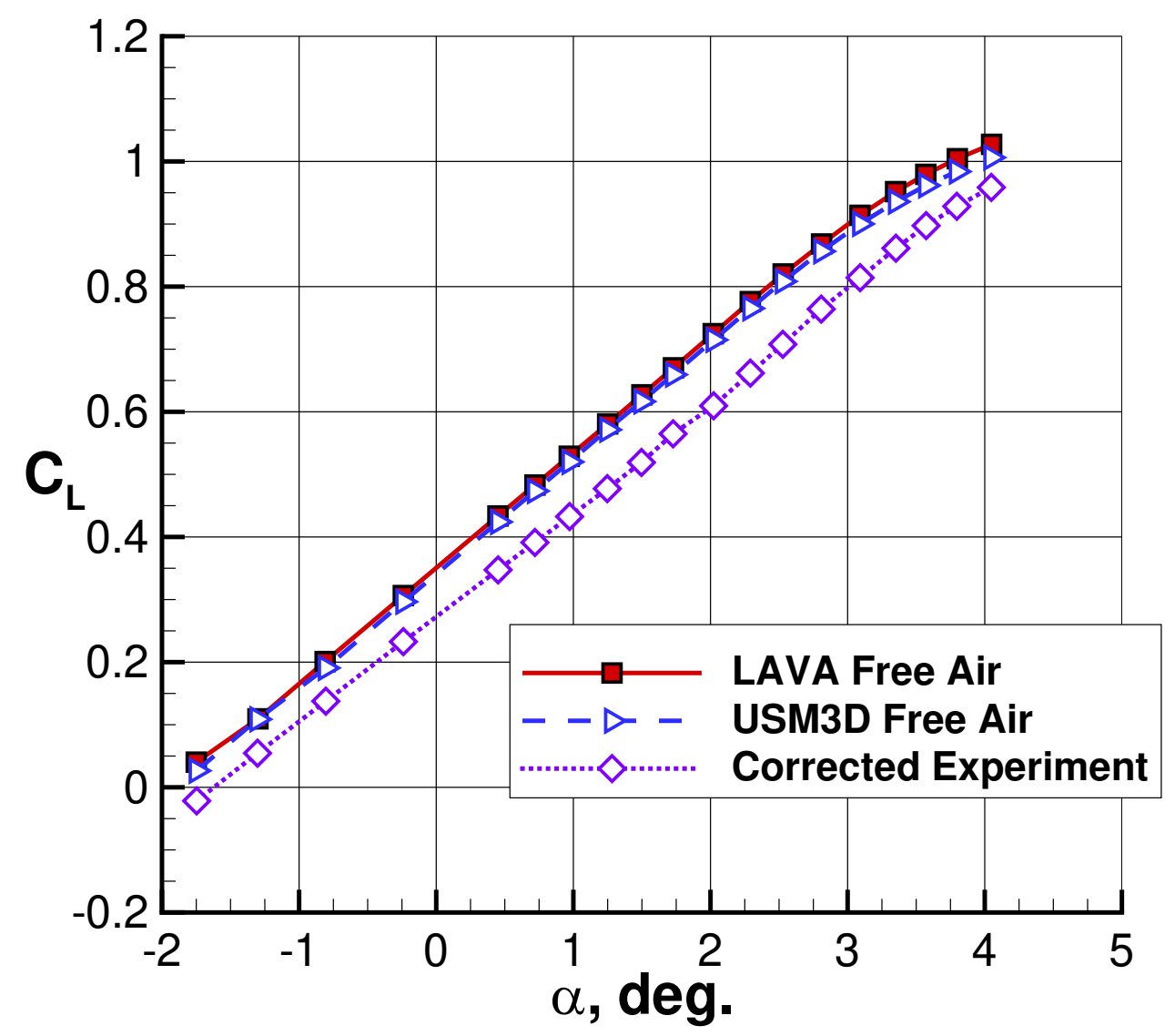

- Conditions:

$-\mathrm{T}_{\text {Freestream }} \approx 493^{\circ} \mathrm{R}$

- $\mathrm{T}_{\text {Stagnation }} \approx 550{ }^{\circ} \mathrm{R}$

- Mach 0.745

- $R e_{c}=3.31 \times 10^{6}$

$-2^{\circ}<\alpha \lesssim 4^{\circ}$

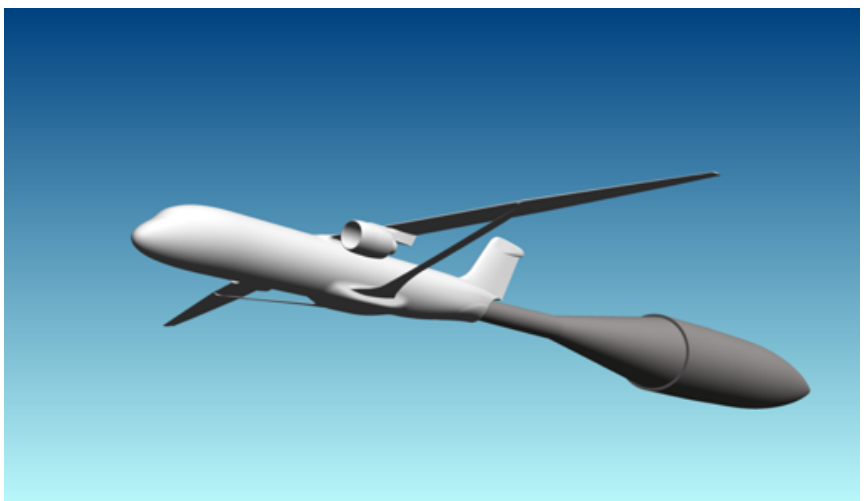




\section{Validation with Wind Tunnel Data}

Free Air - WBSNPV Config 23

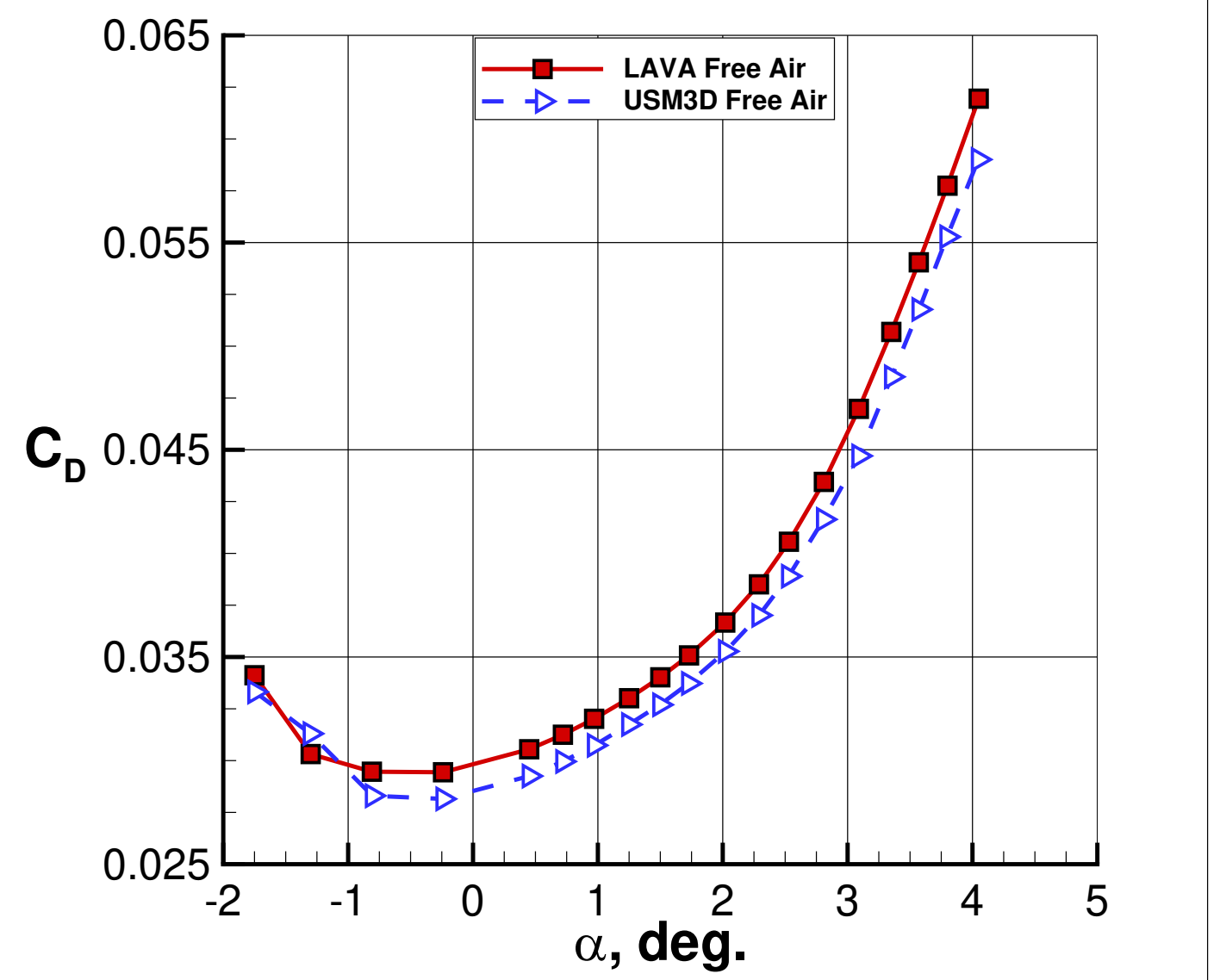

- Conditions:

$-\mathrm{T}_{\text {Freestream }} \approx 493^{\circ} \mathrm{R}$

- $\mathrm{T}_{\text {Stagnation }} \approx 550{ }^{\circ} \mathrm{R}$

- Mach 0.745

- $R e_{c}=3.31 \times 10^{6}$

$-2^{\circ}<\alpha \lesssim 4^{\circ}$

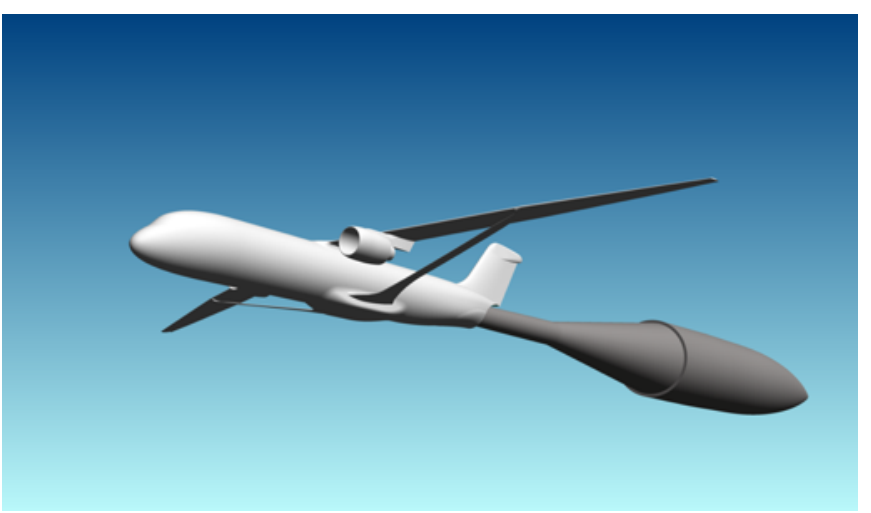




\section{Validation with Wind Tunnel Data}

\section{Free Air - WBSNPV Config 23}

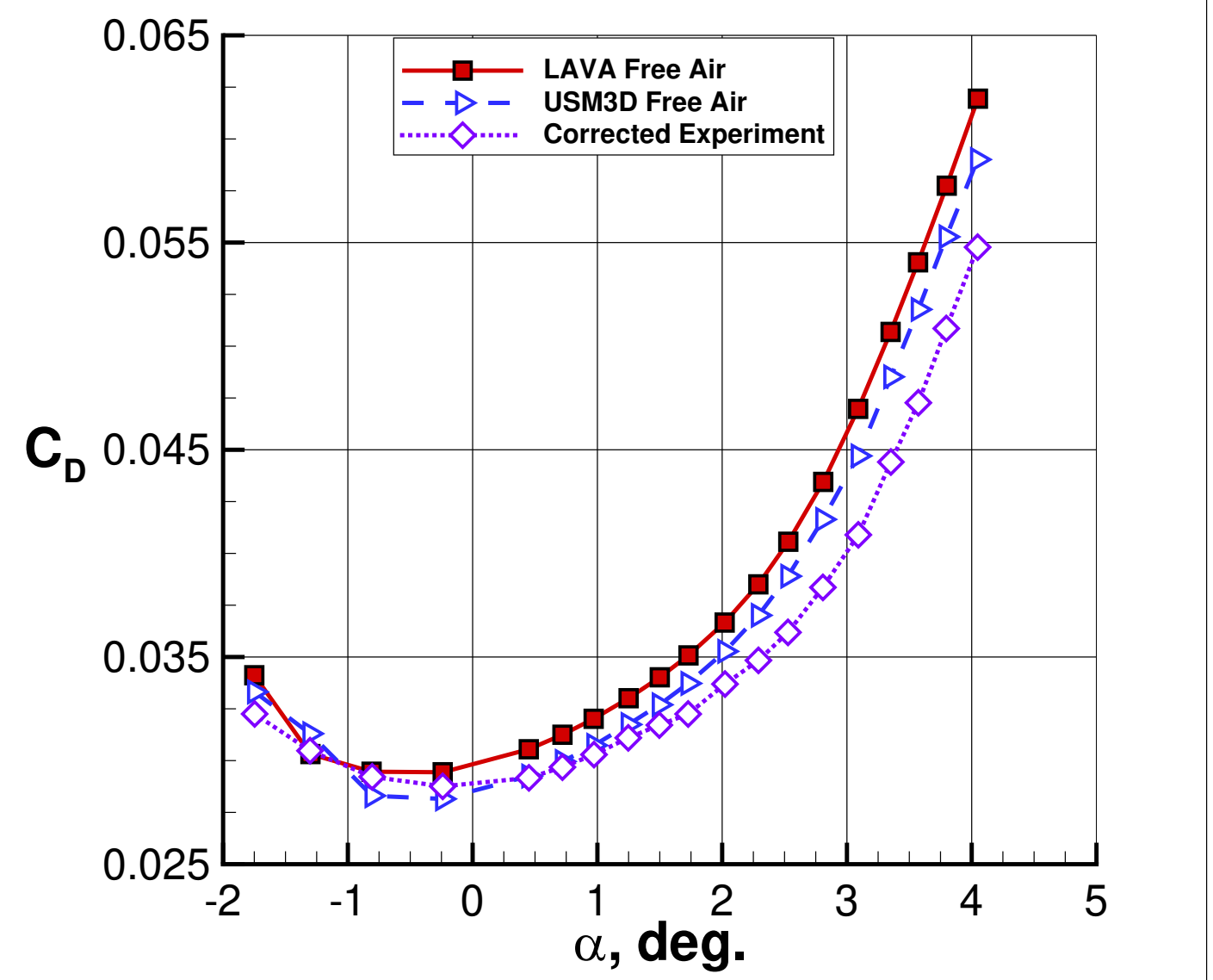

- Conditions:

$-\mathrm{T}_{\text {Freestream }} \approx 493^{\circ} \mathrm{R}$

- $\mathrm{T}_{\text {Stagnation }} \approx 550{ }^{\circ} \mathrm{R}$

- Mach 0.745

- $R e_{c}=3.31 \times 10^{6}$

$-2^{\circ}<\alpha \lesssim 4^{\circ}$

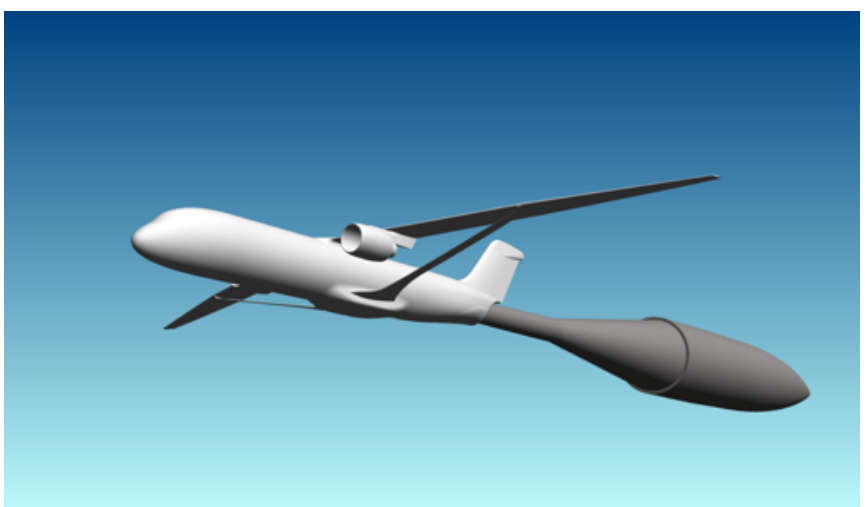




\section{Validation with Wind Tunnel Data}

Free Air - WBSNPV Config 23

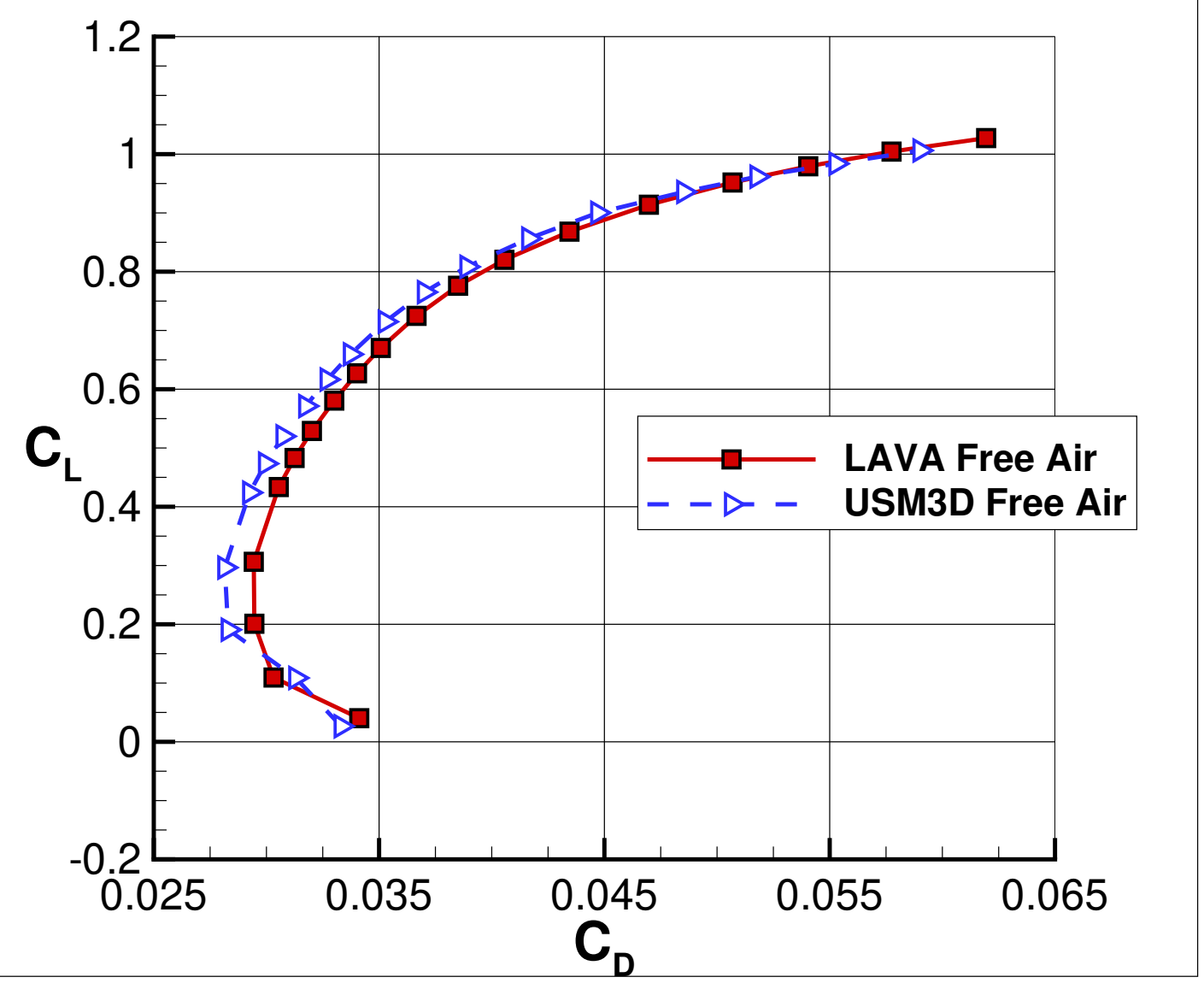

- Conditions:

$-\mathrm{T}_{\text {Freestream }} \approx 493^{\circ} \mathrm{R}$

- $\mathrm{T}_{\text {Stagnation }} \approx 550{ }^{\circ} \mathrm{R}$

- Mach 0.745

- $R e_{c}=3.31 \times 10^{6}$

$-2^{\circ}<\alpha \lesssim 4^{\circ}$

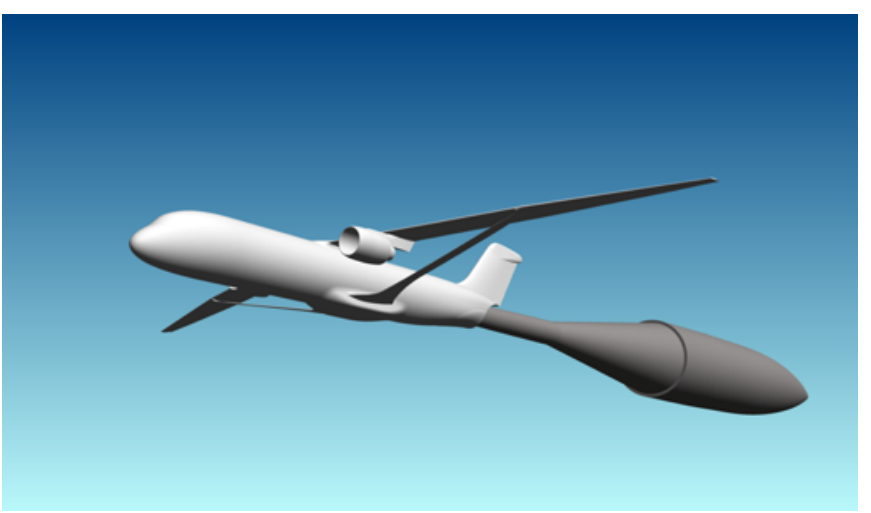




\section{Validation with Wind Tunnel Data}

\section{Free Air - WBSNPV Config 23}

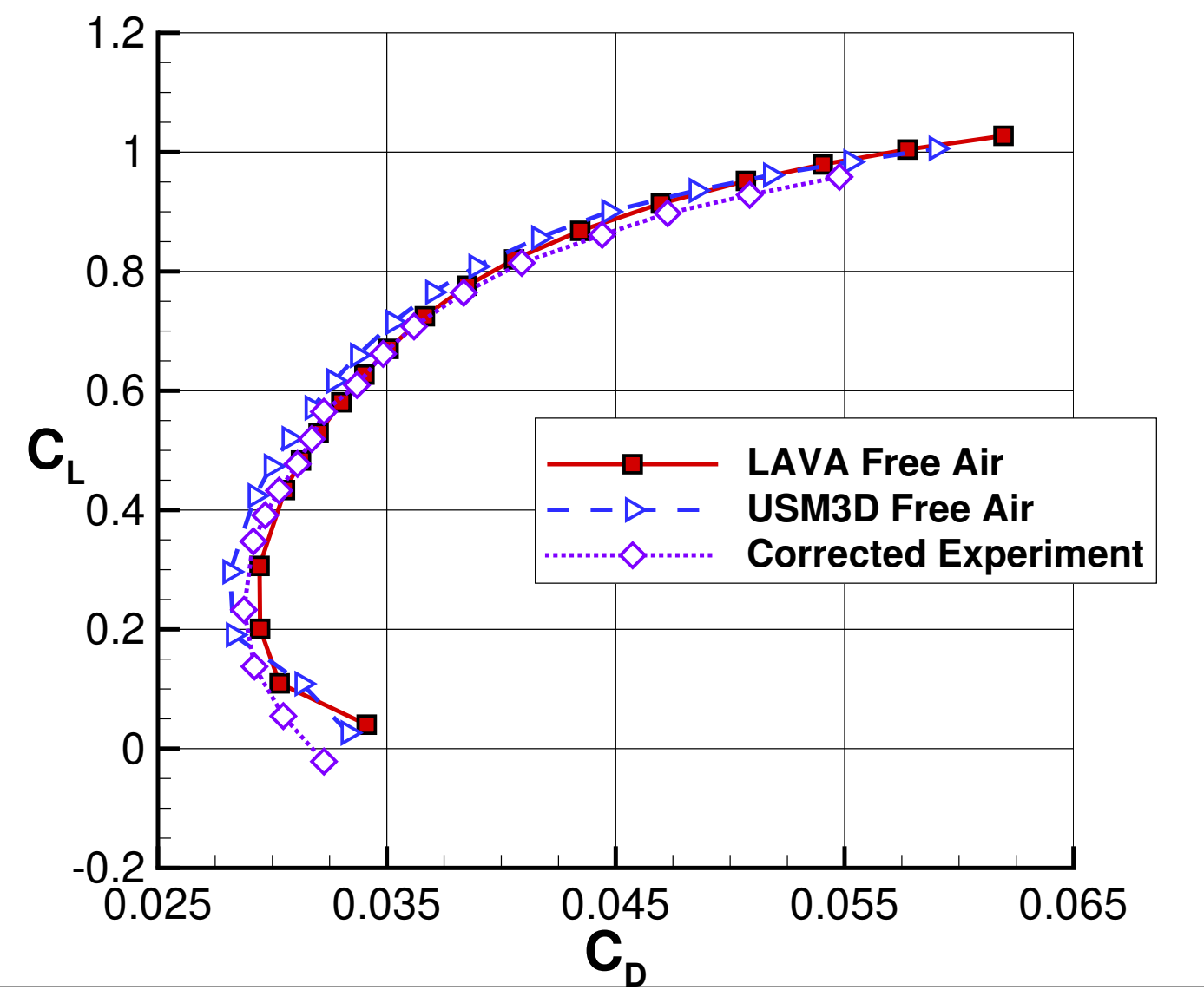

- Conditions:

$-\mathrm{T}_{\text {Freestream }} \approx 493^{\circ} \mathrm{R}$

- $\mathrm{T}_{\text {Stagnation }} \approx 550{ }^{\circ} \mathrm{R}$

- Mach 0.745

- $R e_{c}=3.31 \times 10^{6}$

$-2^{\circ}<\alpha \lesssim 4^{\circ}$

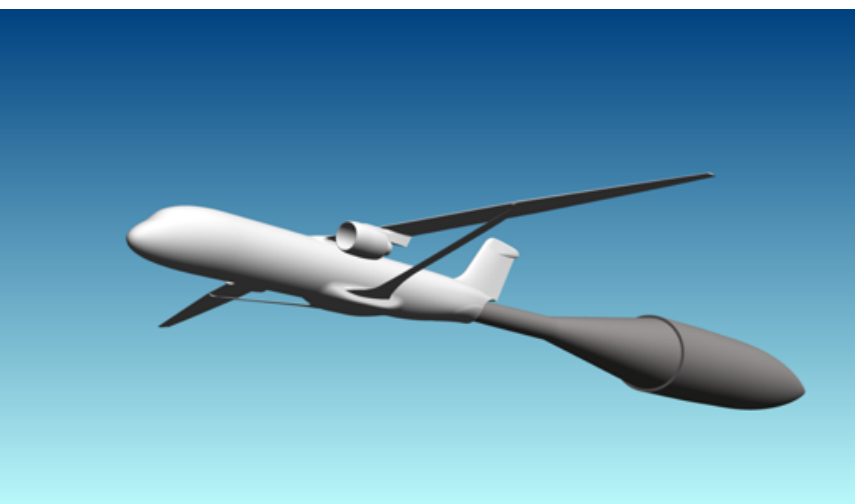




\section{Porous Wall Boundary Condition}

- Porous-wall boundary condition models the baffled slots from the real wind tunnel

- Boundary condition is initialized with a constant plenum pressure

- Boundary condition targets a net mass flow of zero by adjusting plenum pressure

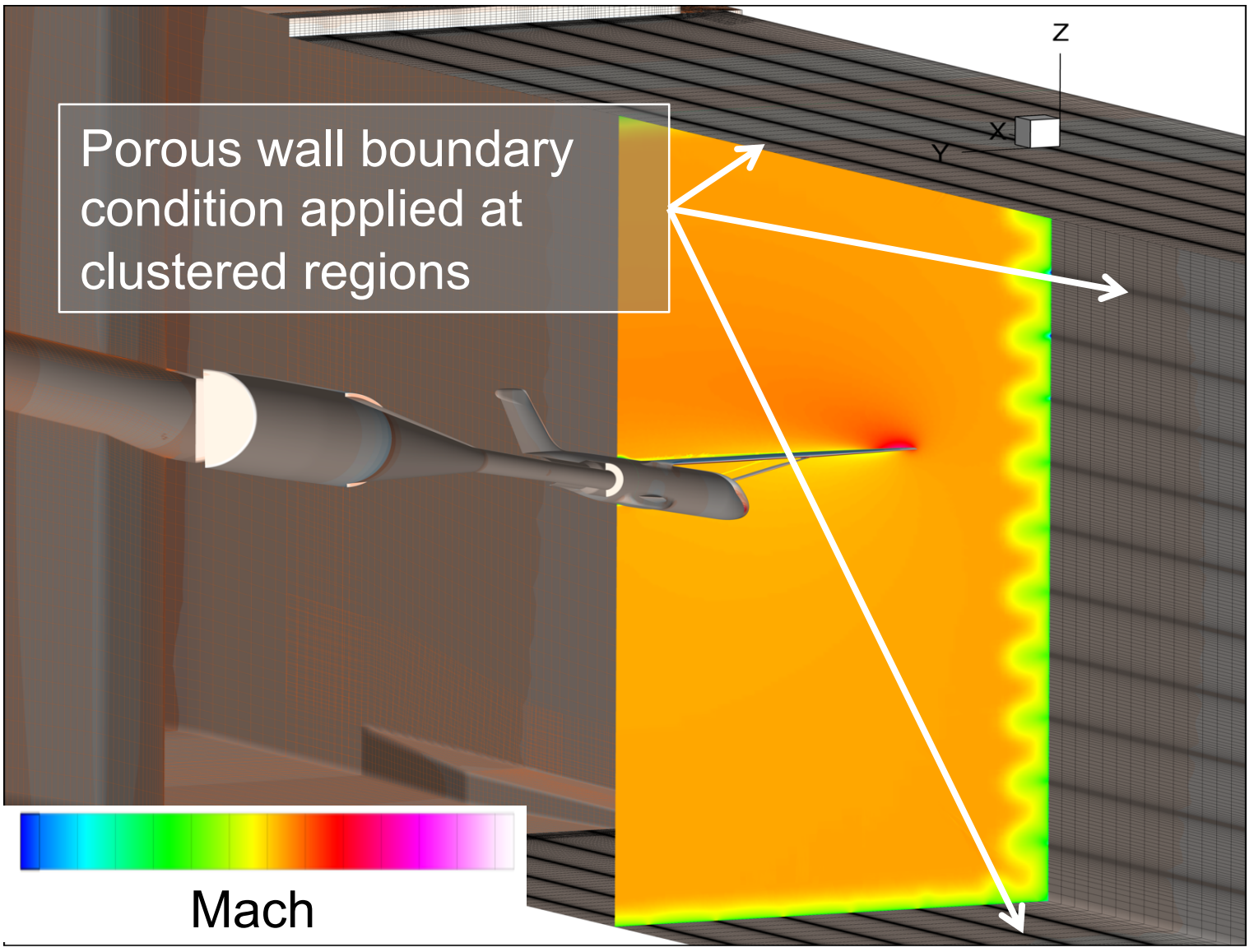

- Baffled geometry is approximated using a porosity factor

Mach contours on cut plane showing the effects of the porous boundary conditions near the wall 


\section{Validation with Wind Tunnel Data Porous Wall - WBSNPV Config 23}

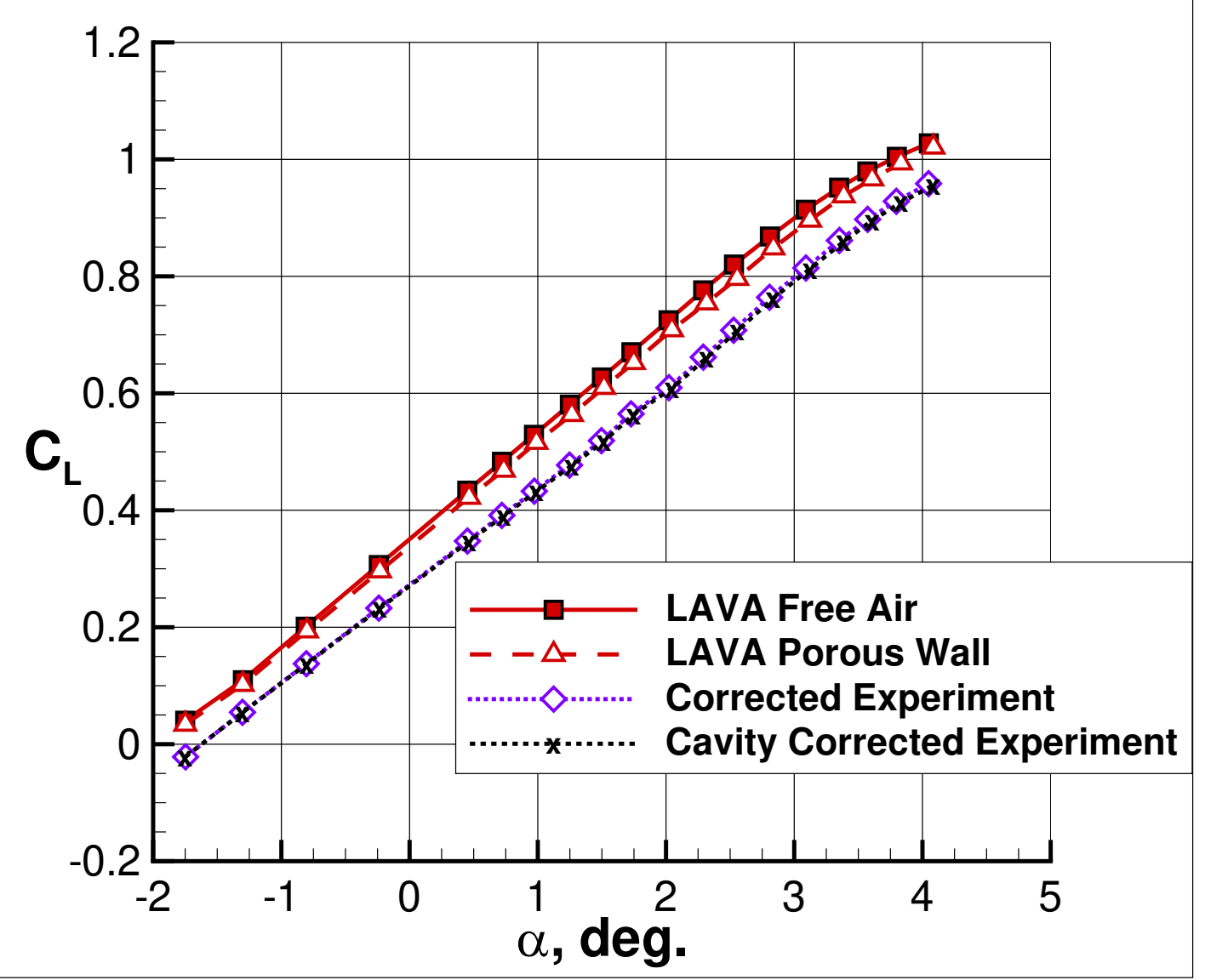

- Conditions:

$-\mathrm{T}_{\text {Freestream }} \approx 493^{\circ} \mathrm{R}$

- $\mathrm{T}_{\text {Stagnation }} \approx 550{ }^{\circ} \mathrm{R}$

- Mach 0.745

- $R e_{c}=3.31 \times 10^{6}$

$-2^{\circ}<\alpha \lesssim 4^{\circ}$

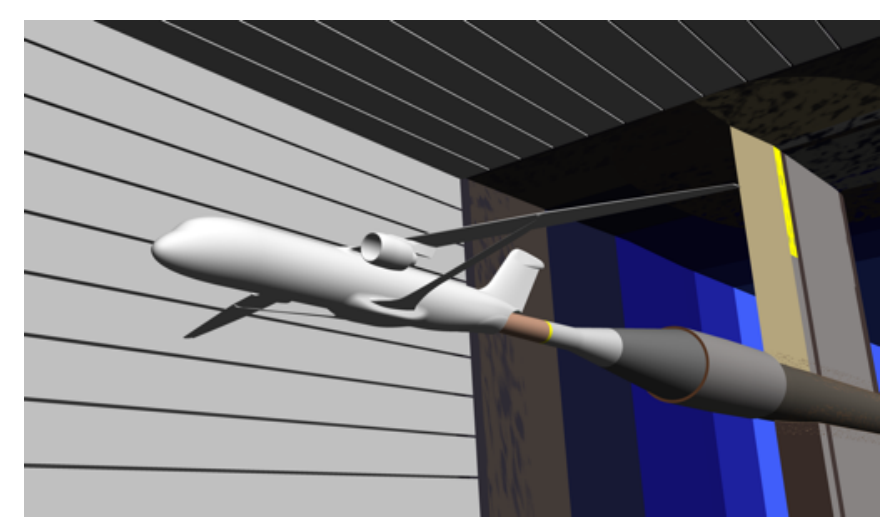




\section{Validation with Wind Tunnel Data Porous Wall - WBSNPV Config 23}

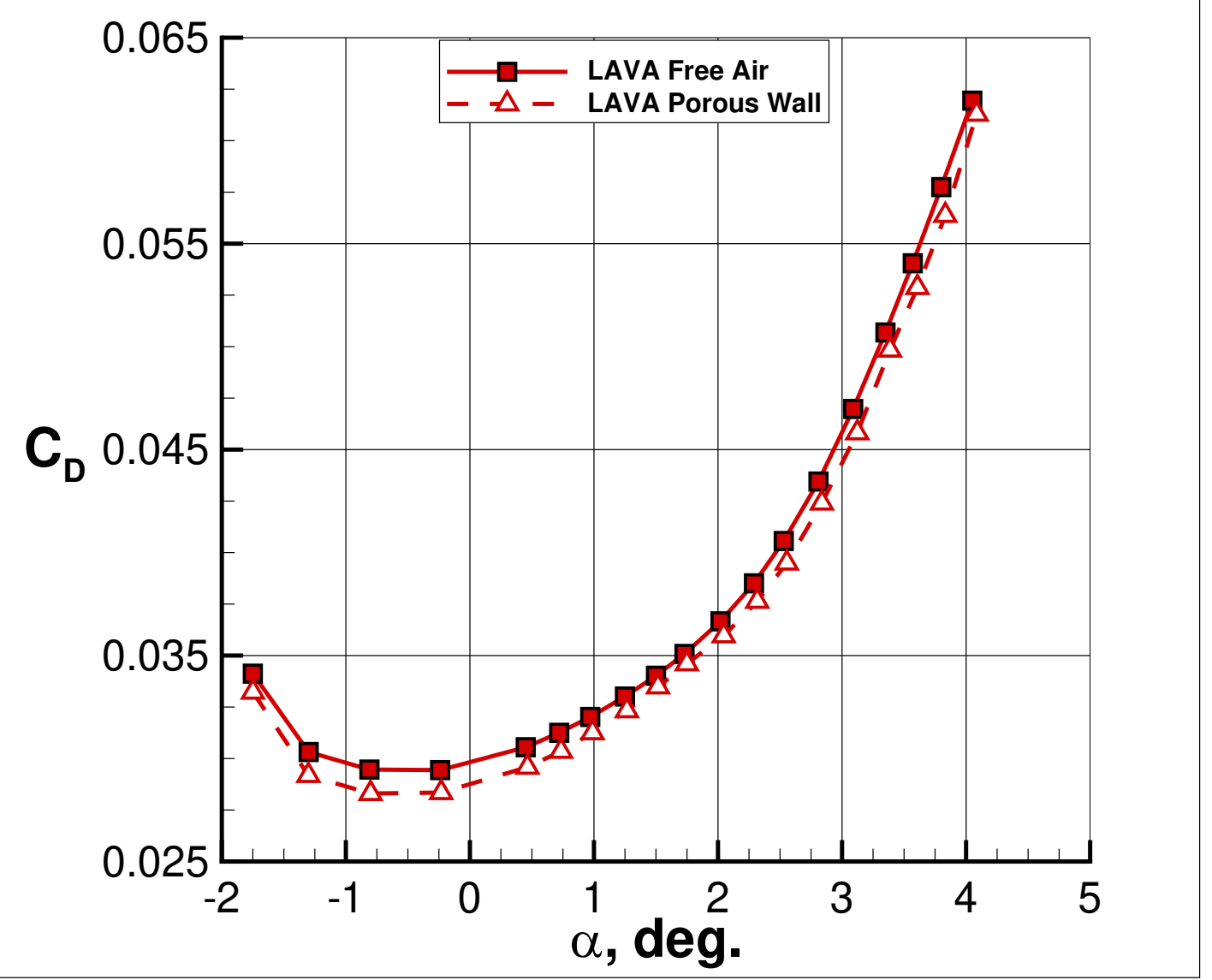

- Conditions:

$-\mathrm{T}_{\text {Freestream }} \approx 493^{\circ} \mathrm{R}$

- $\mathrm{T}_{\text {Stagnation }} \approx 550{ }^{\circ} \mathrm{R}$

- Mach 0.745

- $R e_{c}=3.31 \times 10^{6}$

$-2^{\circ}<\alpha \lesssim 4^{\circ}$

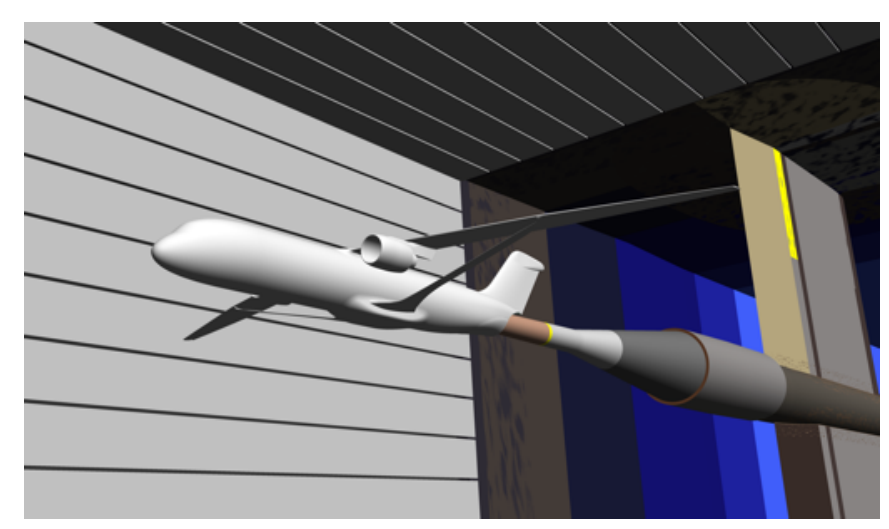




\section{Validation with Wind Tunnel Data Porous Wall - WBSNPV Config 23}

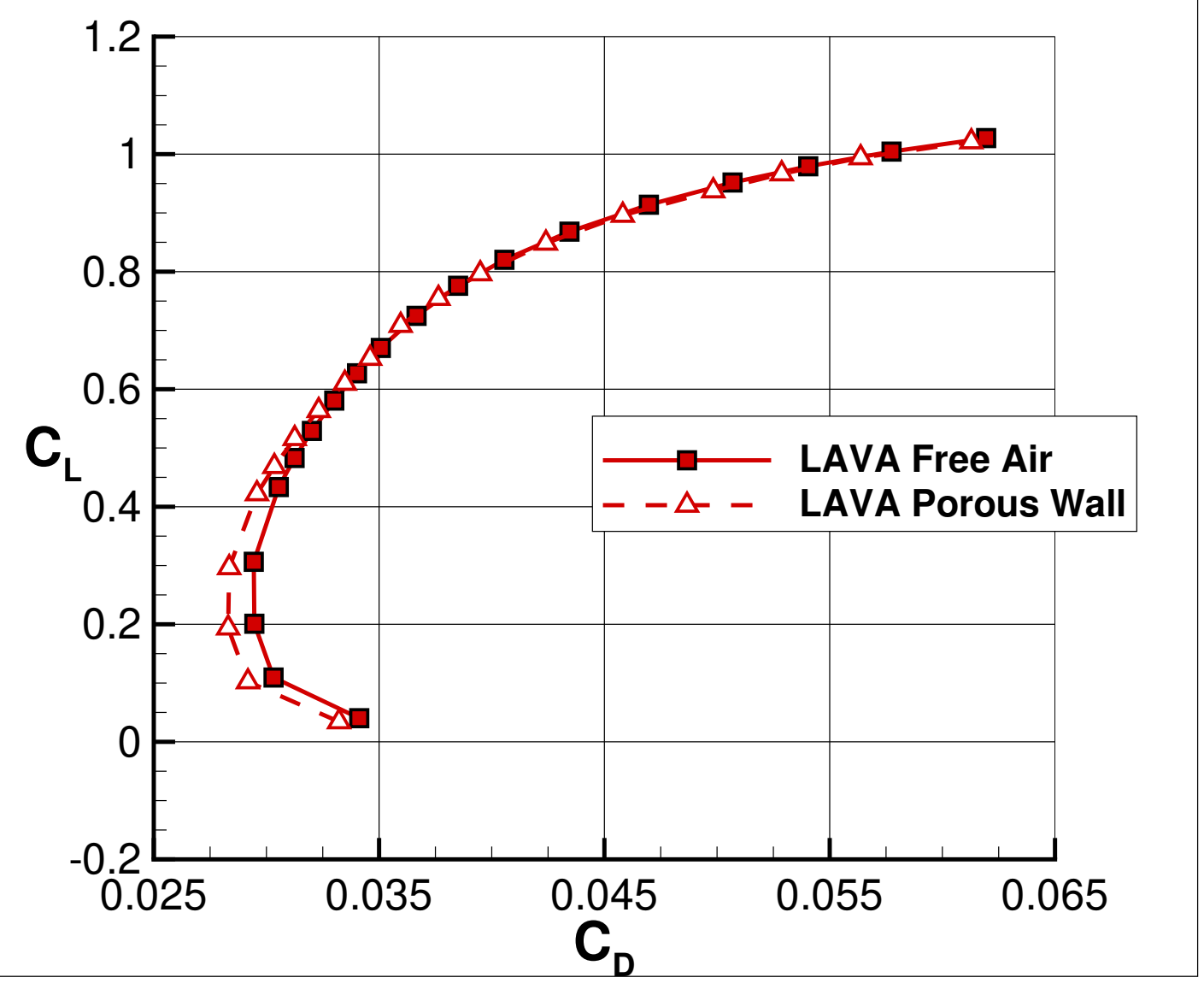

- Conditions:

$-\mathrm{T}_{\text {Freestream }} \approx 493^{\circ} \mathrm{R}$

- $\mathrm{T}_{\text {Stagnation }} \approx 550{ }^{\circ} \mathrm{R}$

- Mach 0.745

- $R e_{c}=3.31 \times 10^{6}$

$-2^{\circ}<\alpha \lesssim 4^{\circ}$

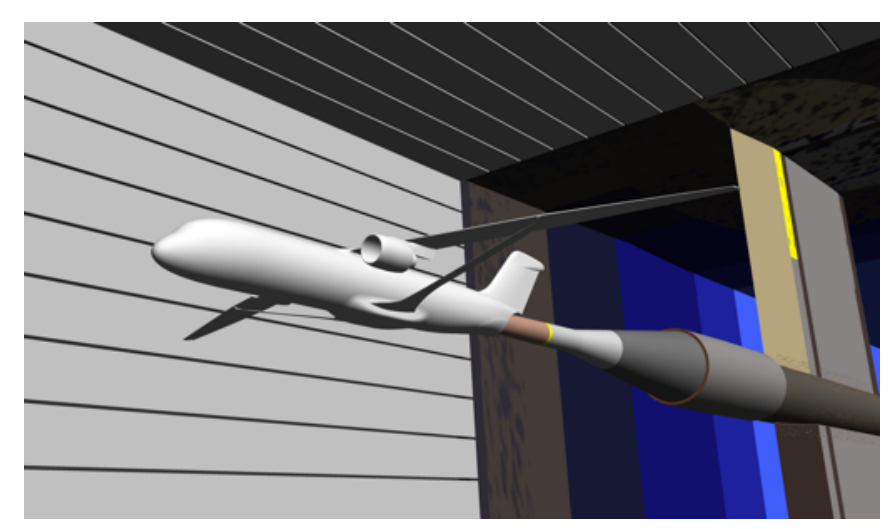




\section{Validation with Wind Tunnel Data Porous Wall - WBSNPV Config 23}

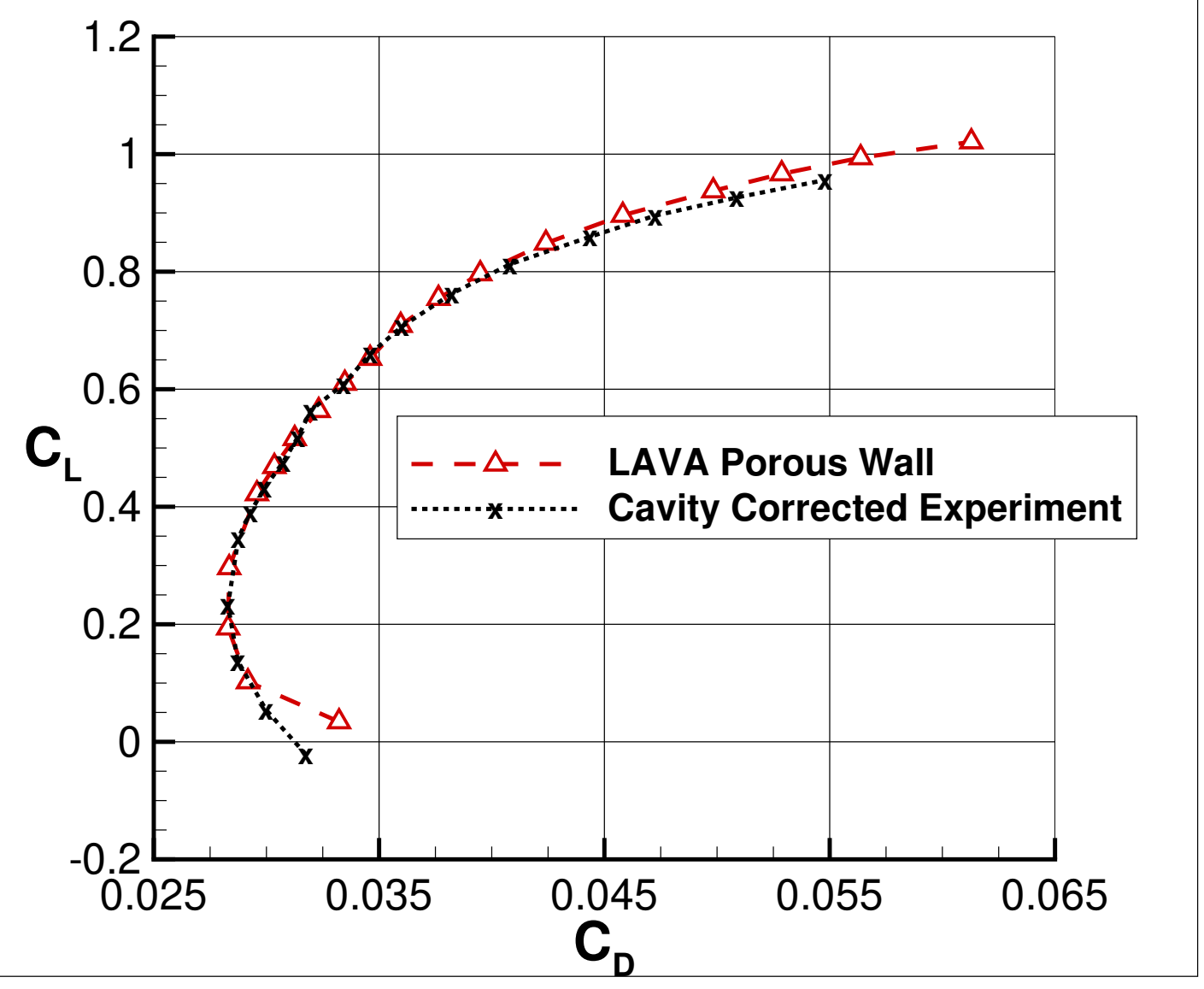

- Conditions:

$-\mathrm{T}_{\text {Freestream }} \approx 493^{\circ} \mathrm{R}$

- $\mathrm{T}_{\text {Stagnation }} \approx 550{ }^{\circ} \mathrm{R}$

- Mach 0.745

- $R e_{c}=3.31 \times 10^{6}$

$-2^{\circ}<\alpha \lesssim 4^{\circ}$

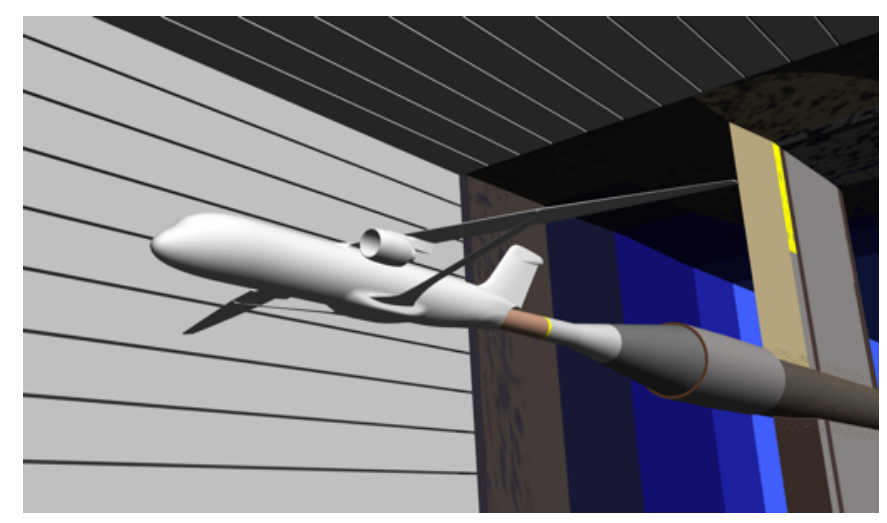




\section{Validation with Wind Tunnel Data}

\section{Free Air - WBSNPV Config 23}

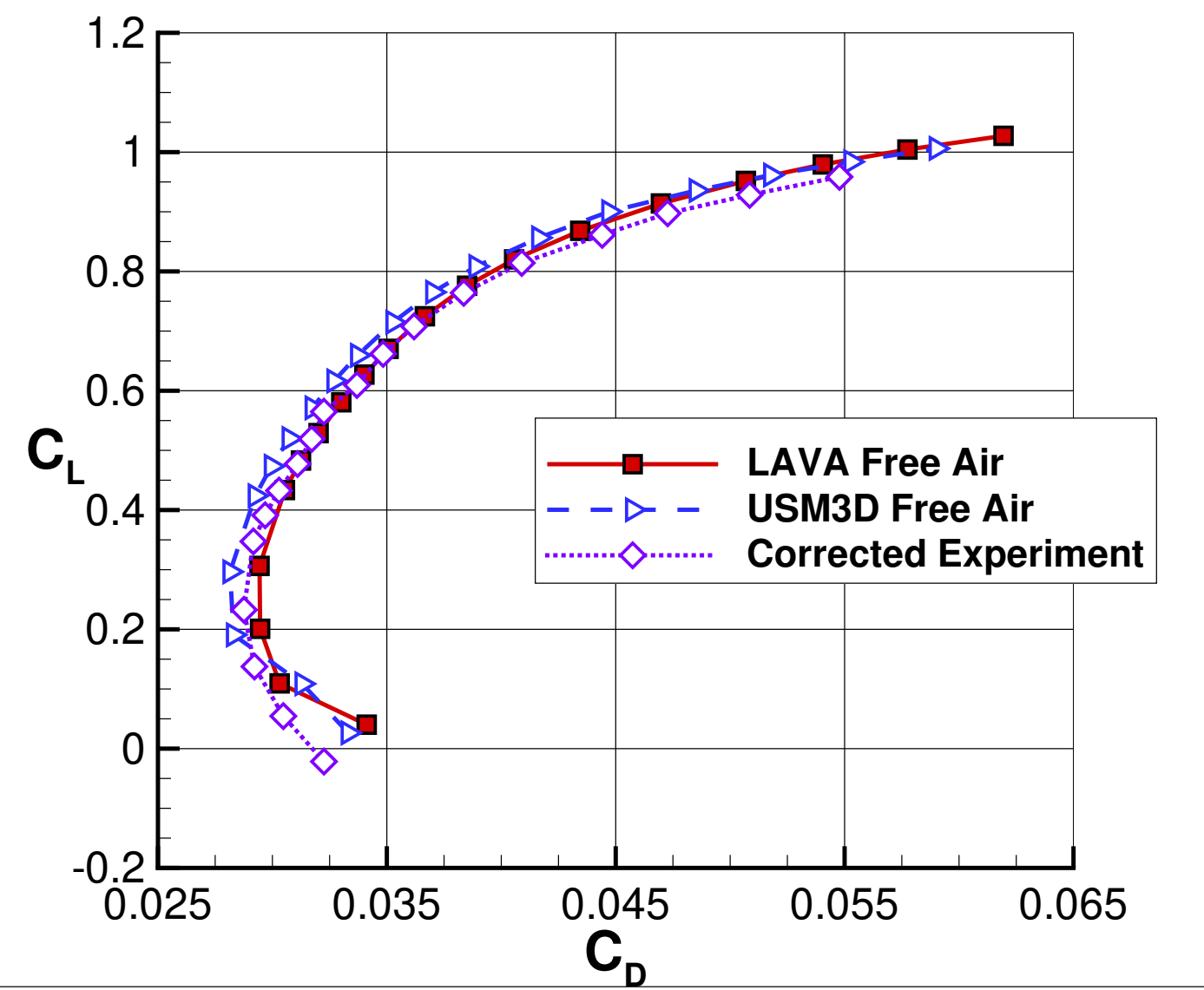

- Conditions:

$-\mathrm{T}_{\text {Freestream }} \approx 493^{\circ} \mathrm{R}$

- $\mathrm{T}_{\text {Stagnation }} \approx 550{ }^{\circ} \mathrm{R}$

- Mach 0.745

- $R e_{c}=3.31 \times 10^{6}$

$-2^{\circ}<\alpha \lesssim 4^{\circ}$

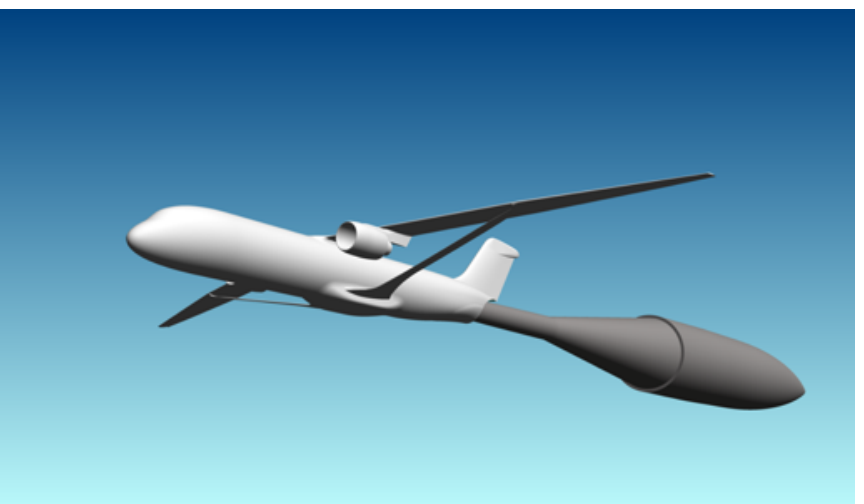




\section{Consistency Across Configurations}

\section{WBSNPV - Config 23}

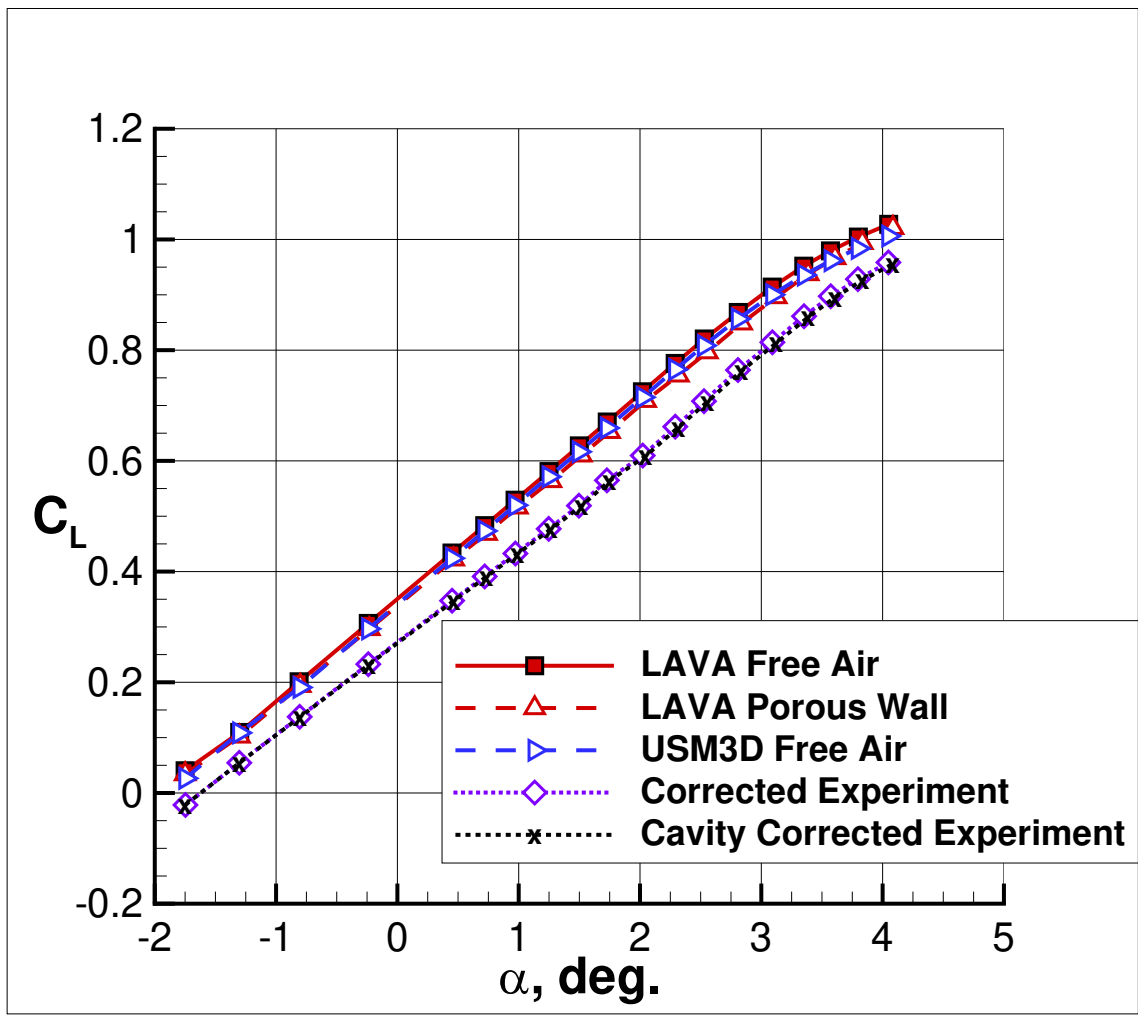

\section{WBSV - Config 21}

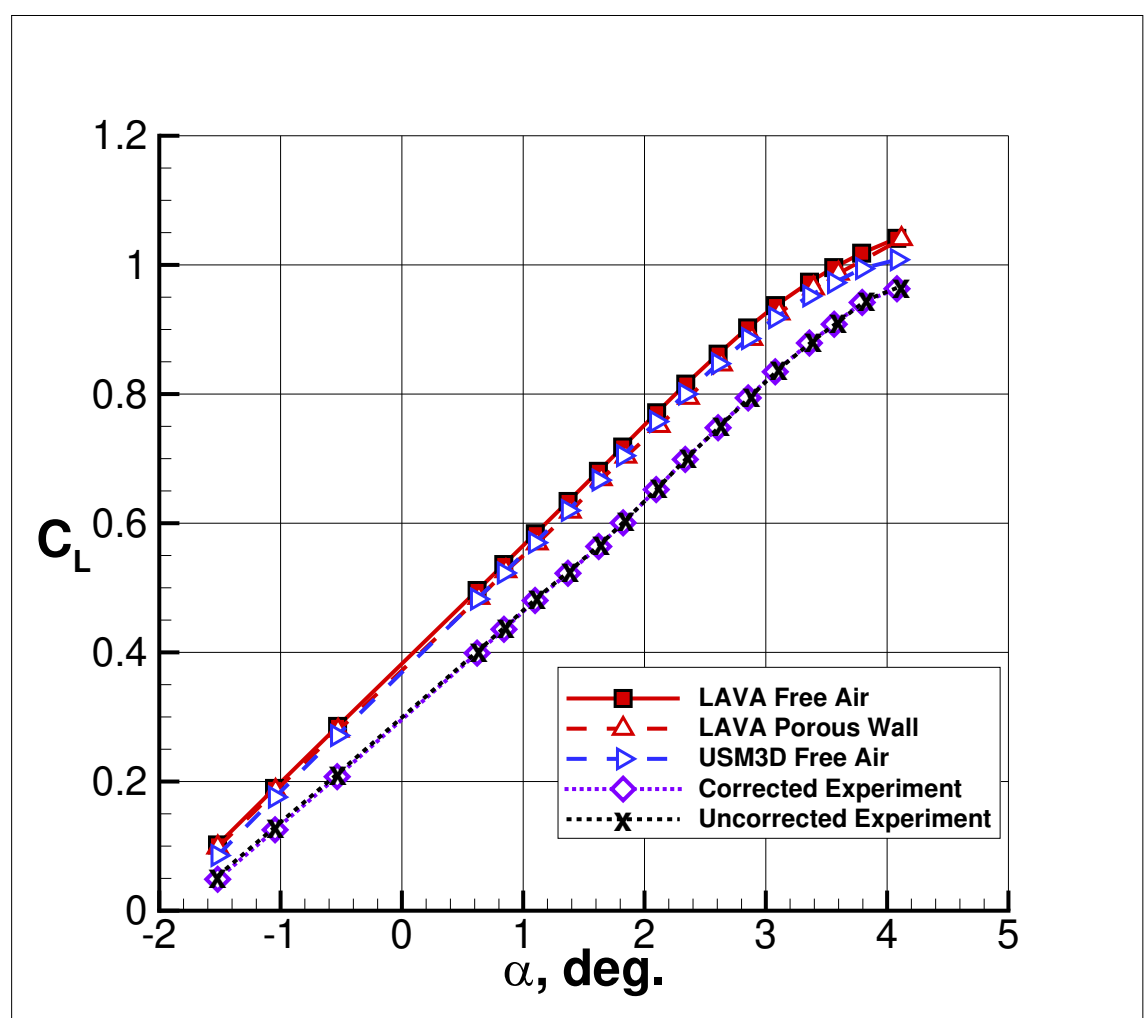

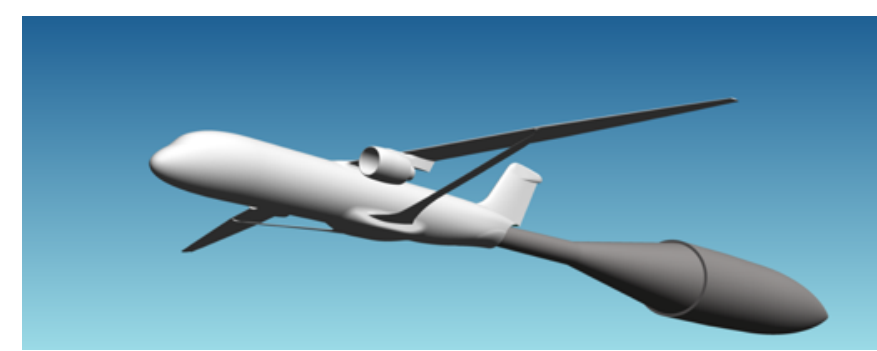

\section{Conditions:}

$\mathrm{T}_{\text {Freestream }} \approx 493^{\circ} \mathrm{R}$

$\mathrm{T}_{\text {Stagnation }} \approx 550^{\circ} \mathrm{R}$ Mach 0.745

$R e_{c}=3.31 \times 10^{6}$

$-2^{\circ}<\alpha \lesssim 4^{\circ}$ 


\section{Validation with Wind Tunnel Data}

\section{Porous Wall - WBSV Config 21}
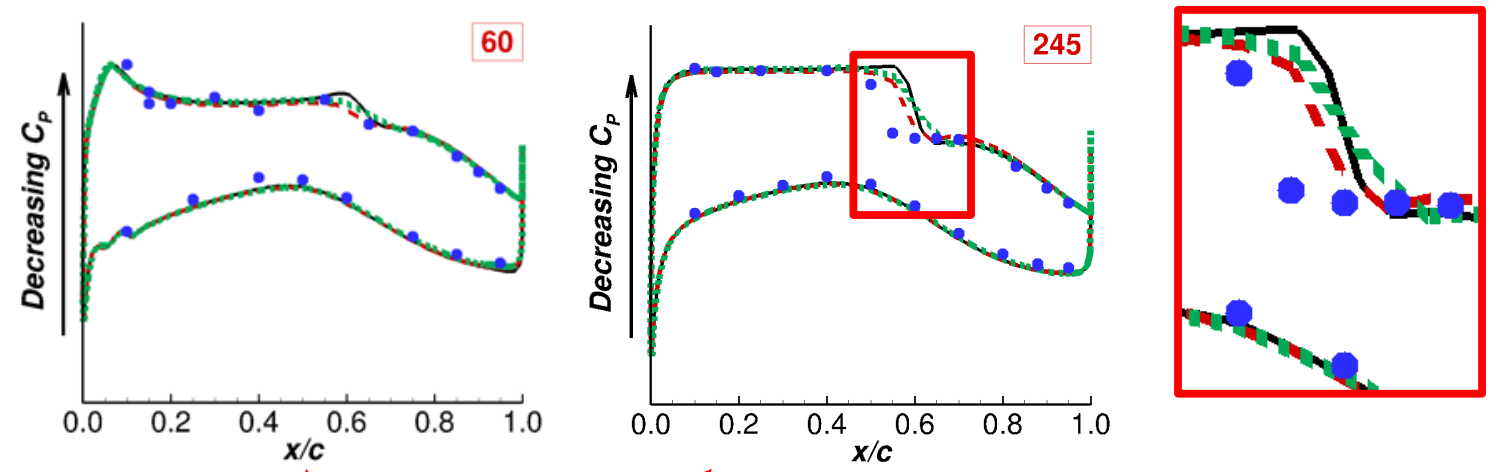

- Conditions:

$-\mathrm{T}_{\text {Freestream }} \approx 493^{\circ} \mathrm{R}$

- $\mathrm{T}_{\text {Stagnation }} \approx 550{ }^{\circ} \mathrm{R}$

- Mach 0.745

- $R e_{c}=3.31 \times 10^{6}$

$-2^{\circ}<\alpha \lesssim 4^{\circ}$
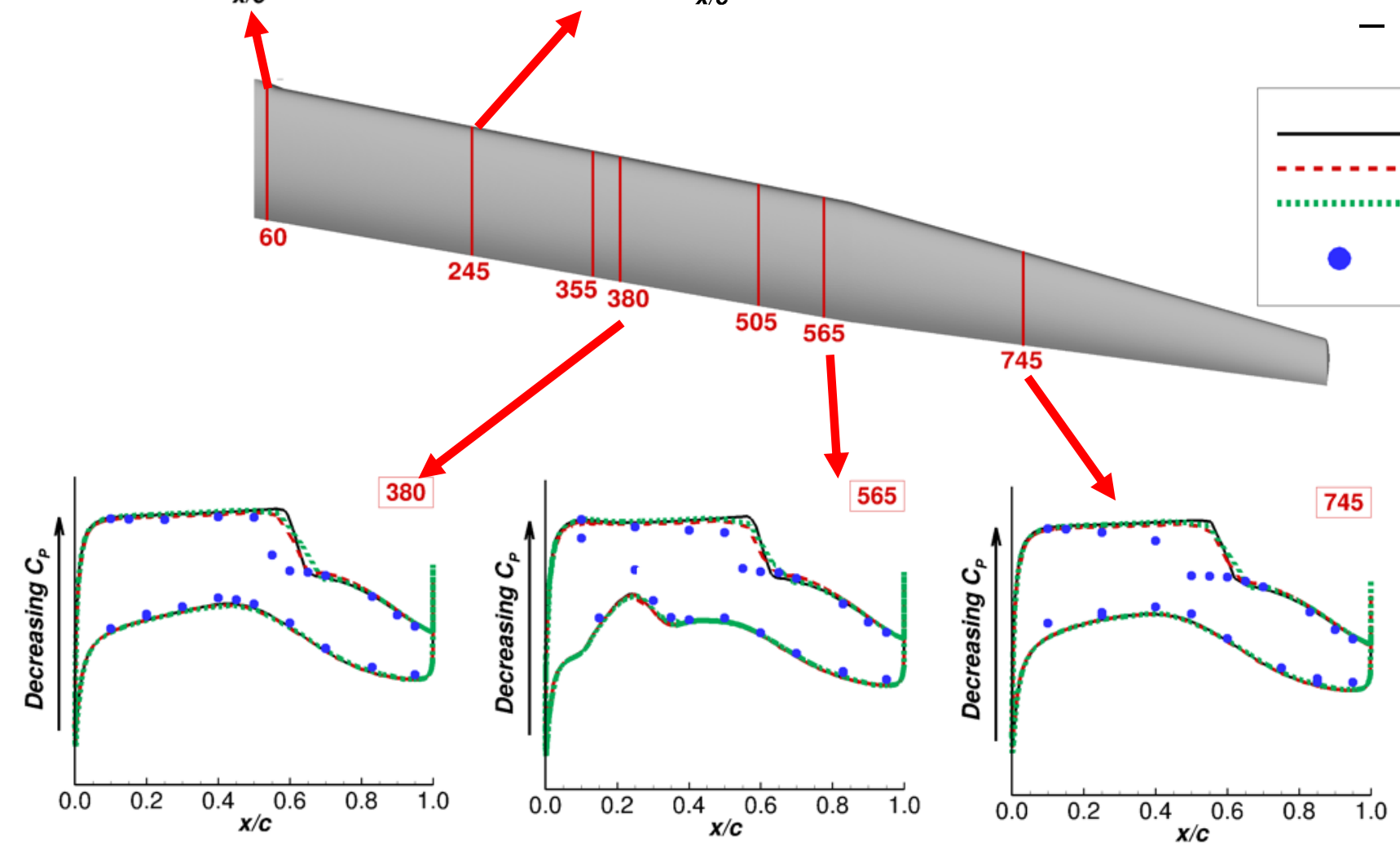

USM3D, Free Air, $\alpha=2.6066^{\circ}$

Porous Wall, $\alpha=2.6350^{\circ}$

LAVA, Free Air, $\alpha=2.6066^{\circ}$

Test 343 - Run 290, $\alpha_{\text {ALPWICS }}=2.6066^{\circ}$

$\alpha_{A L P H U}=2.6350^{\circ}$ 


\section{Approximation of Loaded Deformation}

- Initial 1G geometry

- Designed for $1 \mathrm{G}$ loads experienced during cruise

- Wind tunnel loaded geometry

- Twist data from Model Deformation Measurement (MDM) system

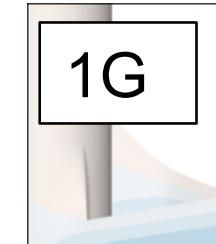

\begin{tabular}{|l|l|l|}
\hline $\begin{array}{l}\text { Refinement } \\
\text { Level }\end{array}$ & $\mathbf{C}_{\mathrm{L}}$ & $\mathbf{C}_{\mathrm{D}}$ \\
\hline $1 \mathrm{G}$ & 0.8480 & 0.03663 \\
\hline Loaded & 0.8446 & 0.03676 \\
\hline $\begin{array}{l}\text { Experiment } \\
\text { Uncorrected }\end{array}$ & 0.7522 & 0.03305 \\
\hline Change & $0.5 \%$ & $\begin{array}{l}1.3 \\
\text { Counts }\end{array}$ \\
\hline
\end{tabular}

\section{Loaded}

LAVA Porous Wall Simulation Using Fine Grid Resolution

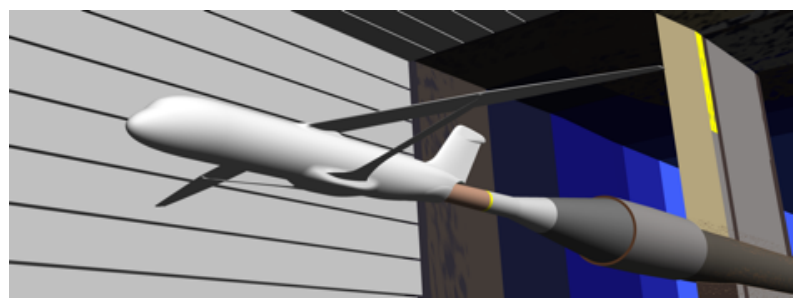




\section{Rounding the Trailing Edge}

- Sharp trailing edge design could not be achieved to due manufacturing tolerances

- Resulted in a model with a rounded bottom portion of trailing edge

- Modified our geometry based on Boeing study showing a shift in CL when simulating an approximation of rounded trailing edge
- Used tolerance to guide modification of existing wing mesh.

- Used CGT to modified the grid to replicate rounding affect

\section{Spanwise cut IIlustrated}

(Not to scale) 


\section{Rounding the Trailing Edge}

- Conditions:

- $\mathrm{T}_{\text {Freestream }} \approx 493^{\circ} \mathrm{R}$

- $\mathrm{T}_{\text {Stagnation }} \approx 550{ }^{\circ} \mathrm{R}$

- Mach 0.745

- $R e_{c}=3.31 \times 10^{6}$

$-2^{\circ}<\alpha \lesssim 4^{\circ}$

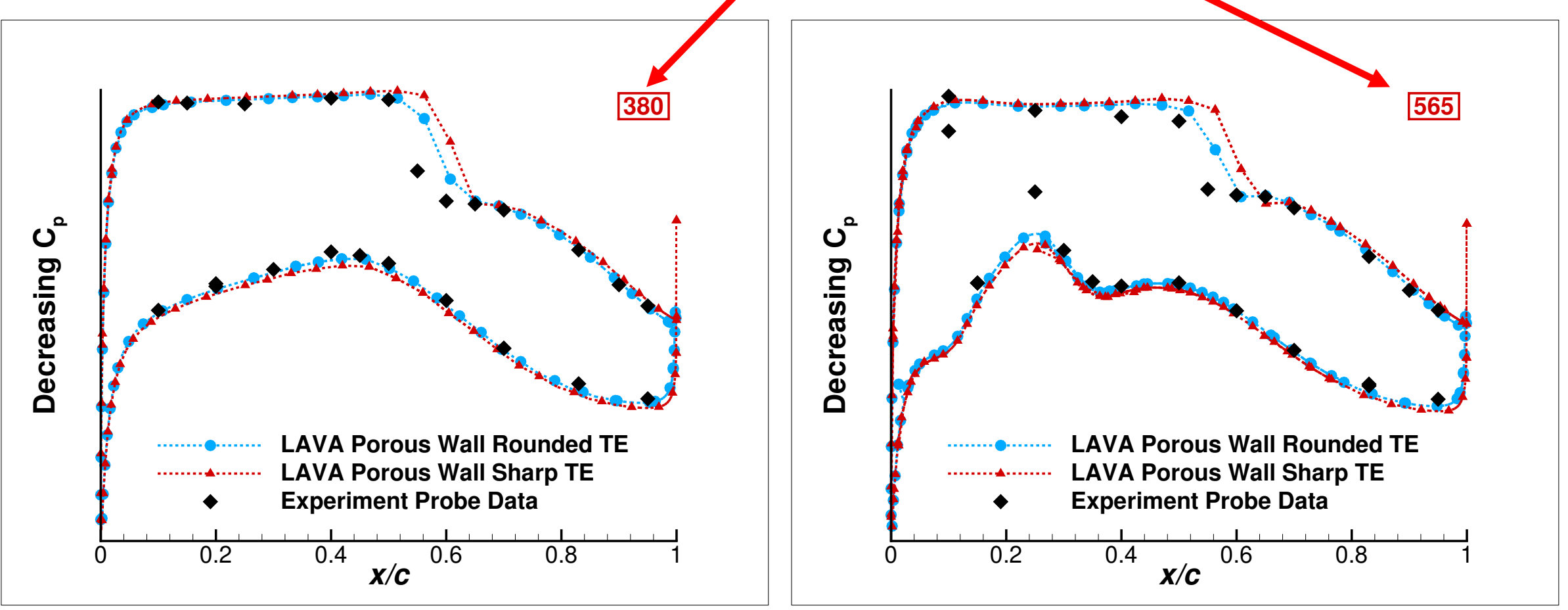




\section{Rounding the Trailing Edge}

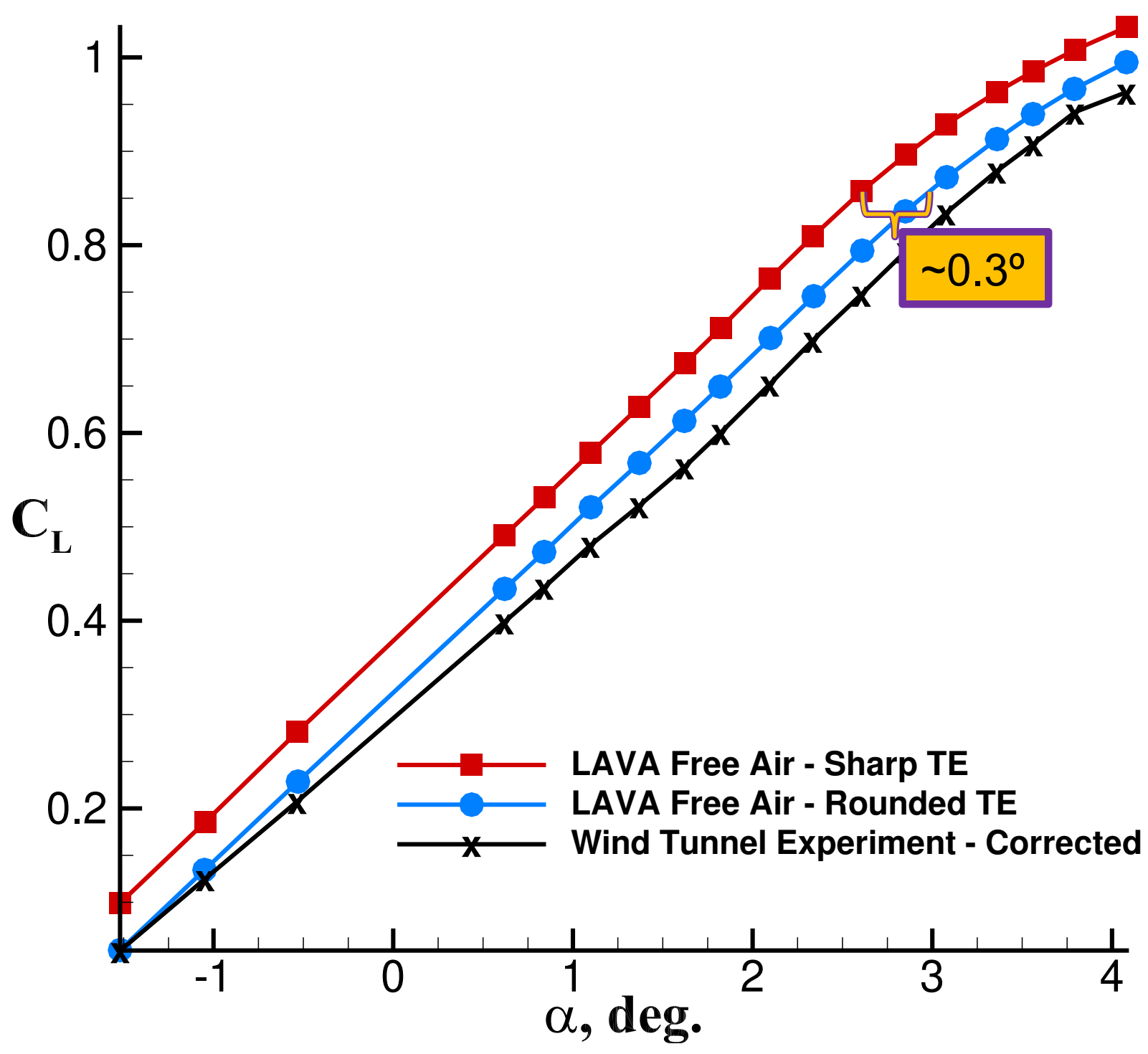

- Conditions:

- $\mathrm{T}_{\text {Freestream }} \approx 493^{\circ} \mathrm{R}$

- $\mathrm{T}_{\text {Stagnation }} \approx 550{ }^{\circ} \mathrm{R}$

- Mach 0.745

- $R e_{c}=3.31 \times 10^{6}$

$-2^{\circ}<\alpha \lesssim 4^{\circ}$

- Reduced difference with experimental $\mathrm{C}_{\mathrm{L}}$ data by $60 \%$ 


\section{Summary}

\section{Findings}

- Code to code comparison essential for determining that the CFD was being solved properly, driving investigations into geometry

- Porous wall shows some improvement over free air:

- In capturing the slope of the $C_{L}-\alpha$ sweep

- Matching L/D performance

- Free air provides significant reduction in resource cost and effort.

- 8 hours vs 3 day run time

- No iterative process to determine Mach number

- Rounded trailing edge showed significant reduction of differences between CFD and experimental lift

- In order to improve comparison with wind tunnel data accurate "as-tested" geometry of the test article is required

\section{Future Work}

- Apply best practices learned from this study to Mach 0.8 of TTBW 


\section{Acknowledgements}

- This project was funded by Advanced Air Transport Technology (AATT) project and its sub-project High Aspect-Ratio Wing (HARW).

- Computer resources were provided by NASA Advanced Supercomputing (NAS) facility.

- The authors would like to acknowledge Michael G. Piotrowski for his contributions to the interpretation and implementation of the porous wall boundary condition into the LAVA solver.

- The authors would like to thank and acknowledge the Boeing team, especially Christopher Droney, Neal Harrison, Michael Beyar, Eric Dickey, and Anthony Sclafani, along with the NASA technical POC for the BAART contracts, Gregory Gatlin. This paper was made possible by them providing data on their model, their simulations, and the wind tunnel test. 


\section{Questions?}




\section{Questions?}




\section{Mach Number for Porous Wall Solutions}

- Porous wall was run with stagnation inflow / subsonic outflow which required specifying a back pressure at the diffuser exit

- Back pressure was used to drive the Mach number in the test section

- Iterative process of adjust back pressure was used to converge to appropriate Mach number

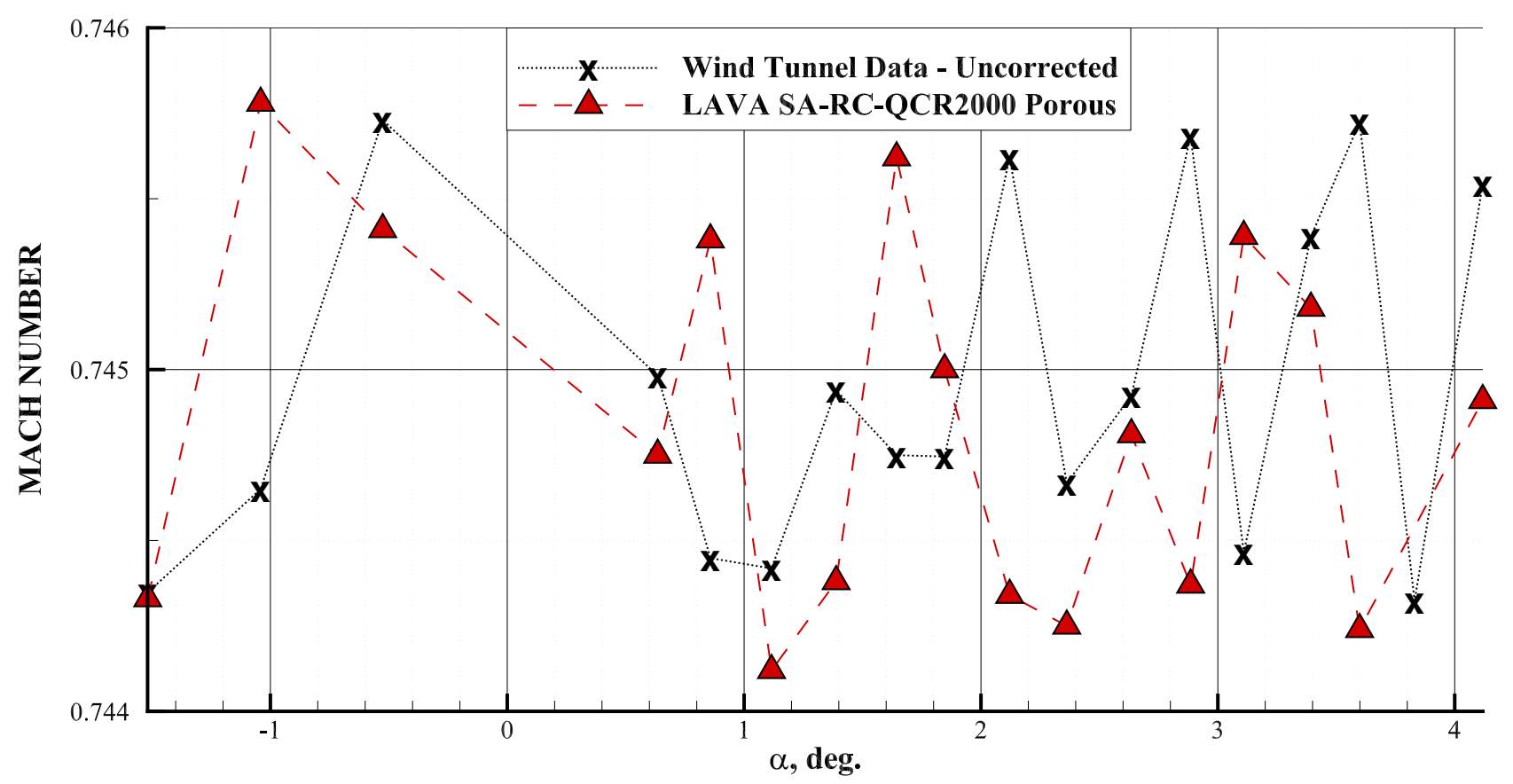

All points within 0.001 from target Mach number 


\section{Validation with Wind Tunnel Data Porous Wall - WBSNPV Config 23}

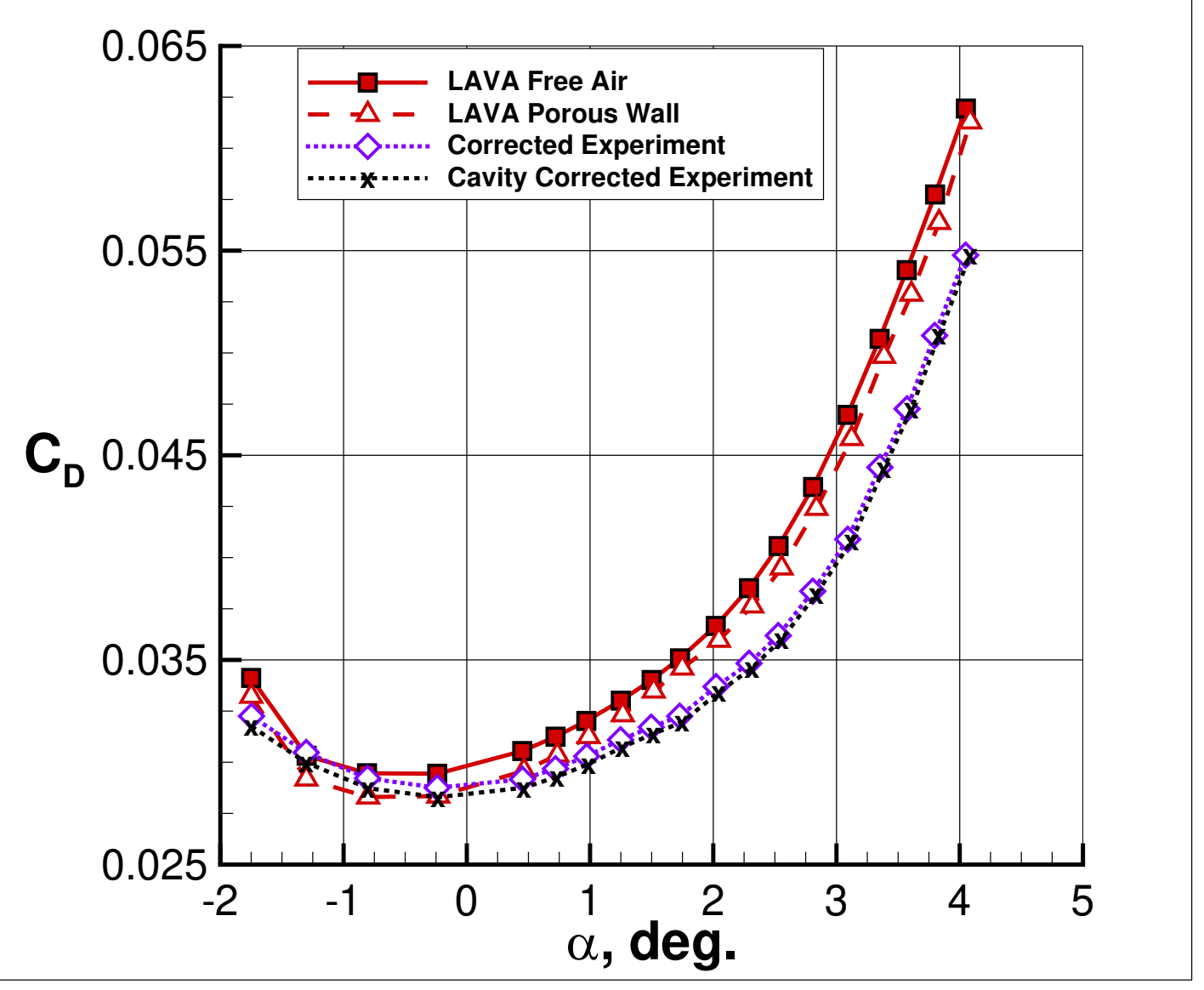

- Conditions:

- $\mathrm{T}_{\text {Freestream }} \approx 493{ }^{\circ} \mathrm{R}$

- $\mathrm{T}_{\text {Stagnation }} \approx 550{ }^{\circ} \mathrm{R}$

- Mach 0.745

- $R e_{c}=3.31 \times 10^{6}$

$-2^{\circ}<\alpha \lesssim 4^{\circ}$

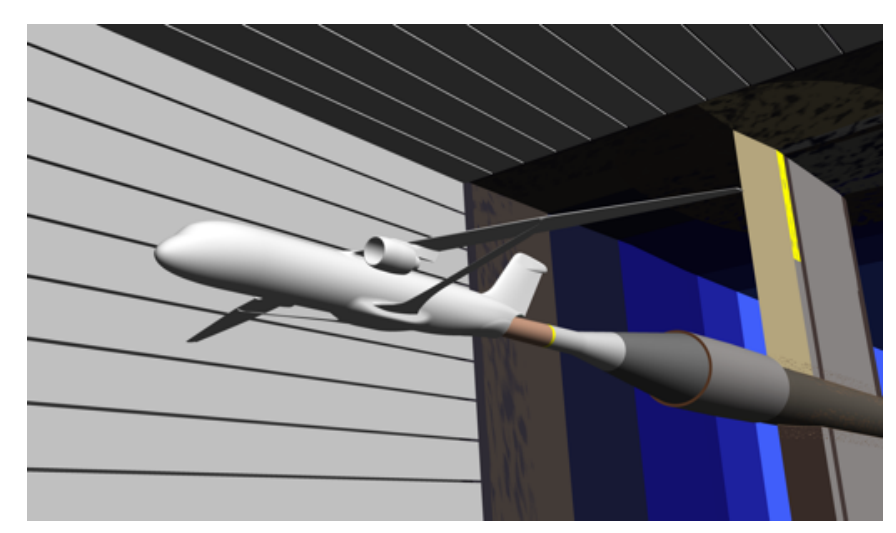

